\title{
Estimação das Importações Indiretas do Complexo Industrial Químico Brasileiro nos anos 2000
}

\section{Estimation of Indirect Imports of the Brazilian Chemical Industry Complex in 2000s}

Thiago de Moraes Moreira* Luiz Carlos Santana Ribeiro**

\begin{abstract}
Resumo: O objetivo deste artigo é estimar as importações brasileiras indiretas de químicos para os anos de 2000, 2005 e 2009. Utilizaram-se dados de matrizes de insumo-produto nacional e internacional, em particular os coeficientes de demanda intermediária por produtos químicos das atividades econômicas. Estimativas como esta são úteis no sentido de melhor mensurar o tamanho do mercado potencial de produtos químicos deslocados pelas importações brasileiras totais, não se limitando apenas às importações diretas. Este mercado potencial corresponderia ao somatório das importações diretas e indiretas, sendo estas últimas referentes aos produtos químicos que se encontram incorporados em toda a pauta de importação brasileira. Ambas as estimativas apresentaram valores crescentes das importações brasileiras indiretas de químicos ao longo dos anos, sendo que a obtida por meio da base internacional apresentou valores relativamente menores. Esta diferença sugere defasagem da estrutura produtiva brasileira, em particular no que diz respeito à eficiência no uso dos insumos químicos. Percebeu-se ainda queda significativa no peso relativo das importações brasileiras com origem nos Estados Unidos, principalmente na primeira metade da década, concomitantemente a um expressivo aumento da participação chinesa.
\end{abstract}

Palavras-chave: Importações indiretas de químicos. Matrizes de insumo-produto. Brasil.

\begin{abstract}
This paper aims to estimate the indirect Brazilian imports of chemicals for the years 2000, 2005 and 2009. Data from national and international input-output matrices were used, in particular the coefficients of intermediate demand for chemical products of economic activities. Estimations like this are useful in order to better measure the size of the potential market for chemical commodities moved by the total Brazilian imports, not limited only to direct imports. This potential market corresponds to the sum of direct and indirect imports, the latter being related to the chemicals that are incorporated throughout the list of Brazilian imports. Both estimation show increasing values of indirect Brazilian imports of chemicals over the years and that obtained by international basis showed relatively

\footnotetext{
* $\quad$ Mestre em economia pelo Instituto de Economia da Universidade Federal do Rio de Janeiro (IE/ UFRJ). Consultor da área de Estratégia da Petrobras, professor de macroeconomia do CORECON/ RJ e membro do Grupo Reindustrialização. E-mail: thiago_m2000@yahoo.com.br

* Doutor em Economia pelo CEDEPLAR/UFMG. Professor do Departamento de Economia da Universidade Federal de Sergipe (UFS), coordenador do Laboratório de Economia Aplicada e Desenvolvimento Regional - LEADER e bolsista de produtividade do CNPq. E-mail: ribeiro. luiz84@gmail.com
} 
lower values. This difference suggests lag of the Brazilian productive structure, particularly regarding to efficiency in use of chemical inputs. It was noticed also a significant decrease in the relative weight of Brazilian imports from the United States, especially in the first half of the decade, concomitantly to a significant increase in Chinese participation.

Keywords: Indirect imports of chemicals. Input-output matrices. Brazil.

JEL Classification: C67; F40.

\section{1 lntrodução}

A economia brasileira passou por diversas mudanças estruturais ao longo dos anos 1990, entre as quais se destacam a abertura comercial no início da década e a adoção da âncora cambial para a estabilização monetária em 1994, as quais levaram a um acelerado crescimento das importações. Segundo dados das Contas Trimestrais do Instituto Brasileiro de Geografia e Estatística (IBGE), entre 1991 e 1999, a expansão das importações de bens e serviços, em termos reais, ocorreu a um ritmo médio de $10 \%$ ao ano. Nos anos 2000, por sua vez, a despeito da implementação de novo regime de política macroeconômica feita ao final da década de 1990, o qual pôs fim à âncora cambial e deixou a taxa de câmbio flutuar (MOREIRA; RIBEIRO, 2013), um dos movimentos macroeconômicos mais importantes continuou sendo o forte crescimento das importações. Em termos nominais, entre 2000 e 2010, as importações totais saíram de $\mathrm{R} \$ 138,5$ bilhões e alcançaram a cifra de $\mathrm{R} \$ 448,8$ bilhões, um crescimento médio de $12,5 \%$ ao ano, conforme apontado pelos dados das Contas Trimestrais.

No que se refere às atividades econômicas, a indústria química ${ }^{1}$ sempre teve peso significativo nas importações brasileiras na década de 2000. Segundo dados da Fundação Centro de Estudos do Comércio Exterior (Funcex), os valores importados de produtos da indústria química saíram de U\$ 11,8 bilhões em 2000 (21,2\% do total de importações de bens) e atingiram US\$ 38,1 bilhões em 2010 (21\% do total importado de bens), uma expansão média de 12,4\% ao ano, em linha com o crescimento nominal das importações totais. Com base nos índices de preços de importação (em US\$) das atividades pertencentes à indústria química, e utilizando a estrutura de ponderação média calculada a partir dos valores de importação entre 2000 e $2010,{ }^{2}$ estima-se que os preços dos produtos químicos importados neste

1 Com base na Classificação Nacional de Atividade Econômica (CNAE) na versão 2.0, o conceito de indústria química aqui utilizado corresponde às atividades de "Produtos químicos", "Produtos farmoquímicos e farmacêuticos" e "Produtos de borracha e de material plástico". Na CNAE 1.0, na qual ainda estão baseados os dados de insumo-produto brasileiros utilizados neste trabalho, a única diferença é que a atividade de "Produtos farmoquímicos e farmacêuticos" correspondia a um subgrupo da atividade de "Produtos químicos". Como veremos mais adiante, na matriz brasileira a atividade de "Produtos químicos" aparece de forma mais detalhada. De todo modo, a indústria química mencionada neste trabalho faz sempre referência ao conjunto das atividades mencionadas acima.

2 A estrutura de ponderação média calculada foi a seguinte: $71,5 \%$ de produtos químicos, 17,6\%, 
período cresceram a um ritmo médio anual de 4,8\%. Logo, o crescimento real das importações diretas de produtos químicos foi de aproximadamente $7,6 \%$.

Vale ressaltar o papel estratégico desta indústria. Ribeiro (2010) e Ribeiro et al. (2010) demonstraram empiricamente que as atividades relacionadas à indústria de químicos usualmente são caracterizadas como setores-chave, ${ }^{3}$ isto é, apresentam os encadeamentos tanto a jusante (forwards linkages) quanto a montante (backwards linkages) acima da média da estrutura econômica. Em outras palavras, tais segmentos podem ser considerados estratégicos do ponto de vista de políticas que induzem o crescimento econômico, já que eles geram elevados efeitos multiplicadores na economia (PRADO, 1981; GUILHOTO et al., 1994). O forte crescimento das importações de produtos da indústria química, por sua vez, tende a provocar redução, ou pelo menos impedir a expansão, do potencial das atividades da indústria química de estimular o crescimento das demais atividades na economia brasileira. ${ }^{4}$

A forma tradicional de mensuração das importações dos produtos químicos corresponde à agregação dos valores de produtos químicos estrangeiros adquiridos diretamente por residentes brasileiros. O objetivo principal deste artigo, no entanto, é dimensionar o que chamaremos de importações indiretas de produtos químicos, isto é, o valor destes produtos que se encontram incorporados, na forma de insumos, em outros bens importados. A partir do somatório das importações diretas com as indiretas, tem-se uma noção mais precisa de qual o tamanho efetivo do mercado de produtos da indústria química ocupado pelas importações.

Para a estimação das importações indiretas utilizaremos dados de Matrizes de Insumo Produto (MIP), a partir dos quais faremos dois tipos de estimação das importações indiretas de químicos. O primeiro, mais simples, utilizará como base apenas a estrutura produtiva brasileira, enquanto o segundo fará uso de um conjunto de matrizes internacionais.

Pode-se considerar, nesse contexto, que um dos principais avanços do presente estudo é utilizar associadamente dois conjuntos de MIP no sentido de oferecer uma análise comparativa da mensuração das importações indiretas de produtos químicos para o Brasil em diferentes momentos da década de 2000, apre-

farmoquímicos e farmacêuticos e 10,9\% de produtos de borracha e plástico.

3 Conceito que ficou conhecido na literatura a partir dos índices de ligação criados por Hirschman (1958) e Rasmussen (1958).

4 Calculando os Índices de ligações Rasmussen-Hirschman com base nas Matrizes de Insumo Produto (MIP) brasileiras, verificam-se quedas tanto no índice de ligação para trás (montante) quanto para frente (jusante) na década de 2000. Tomando como referência a MIP oficial de 2000 e uma estimada de 2009 (ambas serão utilizadas neste trabalho e mencionadas ao longo do texto), a média aritmética simples dos índices para trás das atividades que compõem a indústria química foi de 1,21, enquanto em 2009 essa média foi de 1,13. Com relação ao índice de ligação para frente, a média neste mesmo período passou de 0,97 para 0,84. Vale lembrar que valores acima (abaixo) de 1 significam poder de encadeamento acima (abaixo) da média da economia. 
sentando também dois métodos que poderão ser replicados para a estimativa de importações indiretas de outros produtos.

Além desta introdução, o trabalho está estruturado da seguinte forma: a segunda seção apresenta especificidades da indústria química no Brasil. Na terceira seção definiremos, grosso modo, de que forma os dados de insumo-produto foram utilizados para o cômputo das importações indiretas. Ademais, serão apresentadas as características básicas dos dados das MIP brasileiras utilizadas, a partir dos quais apresentaremos os resultados da primeira estimativa de importações indiretas de produtos químicos. Já na quarta seção, apresentaremos o conjunto de dados internacionais de insumo-produto consolidados pelo projeto denominado World Input Output Database (WIOD). Com base nestes dados, apresentaremos a segunda estimativa das importações indiretas, a qual nos permitirá uma análise mais detalhada considerando as diferenças nas estruturas produtivas dos principais países de origem das importações brasileiras. Na quinta e última seção, apresentaremos as considerações finais.

\section{Especificidades da Indústria Química no Brasil}

Nesta seção apresentaremos alguns dos principais aspectos relativos à estrutura de produção e da demanda de produtos químicos na economia brasileira observados nos pontos extremos da década de 2000. Tratando da demanda de químicos, em 2000 seu valor total (a preços de mercado) foi de $\mathrm{R} \$ 165,1$ bilhões. Os dados setoriais das Contas Nacionais, apresentados nas chamadas Tabelas de Recursos e Usos (TRU), mostram que a principal forma de absorção do referido valor demandando correspondeu ao consumo intermediário, representando 68,3\%, sendo os $31,7 \%$ restantes absorvidos sob a forma de demanda final, dividida, por sua vez, em consumo privado (24,7\%), exportações $(5,2 \%)$ e variação de estoques $(1,8 \%)$. A importância do setor como fornecedor de insumos torna-se ainda mais evidente quando se calcula sua participação na demanda intermediária total por insumos provenientes da indústria de transformação, que em 2000 foi de 23,3\%.

No fim da década de 2000, especificamente em 2009, observou-se um valor de demanda total por produtos químicos de $\mathrm{R} \$ 426,3$ bilhões, um crescimento médio, em termos nominais, de 11,1\% ao ano. A despeito do forte crescimento, os parâmetros estruturais de demanda apresentaram relativa estabilidade ao longo da década em análise, apenas com ligeiro incremento na participação do consumo final. Em 2009, a demanda intermediária correspondia a 66,2\% da demanda total, enquanto a demanda final, a 33,8\%. Destes, $27,1 \%$ foram absorvidos como consumo privado, os mesmos 5,2\%, como exportação e 1,5\%, como variação de estoques. Do total demandado de insumos industriais, os químicos representaram em 2009, 21,9\%, que a despeito da queda em relação ao início da década, ainda 
representa uma participação bastante elevada para um único segmento industrial. Os dados evidenciam, portanto, que o mercado interno representa o principal driver de crescimento da demanda de químicos na economia brasileira.

No que se refere à oferta, destaque para a participação da produção química brasileira tanto no Valor Bruto da Produção (VBP) quanto no Valor Adicionado Bruto (VAB ou PIB) da indústria de transformação brasileira no período em análise. Denota-se que o VBP total da indústria química em 2000 foi de $\mathrm{R} \$ 107,3$ bilhões, 16,8\% do VBP total da indústria de transformação, praticamente o mesmo percentual de participação no VAB desta mesma indústria neste ano, a qual foi de $16,9 \%$, equivalente a $R \$ 29,7$ bilhões. Com relação ao PIB total da economia brasileira (a preços básicos), a contribuição da indústria química foi, em 2000, equivalente a 2,9\%. Já em 2009, o VBP total da indústria química resultou em $R \$ 256,5$ bilhões, expansão média, em termos nominais, de 10,2\% ao ano, ritmo inferior ao comportamento observado da demanda. Já o VAB da indústria química registrou em 2009 R \$ 74,6 bilhões, uma expansão média anual de 10,8\%. Quanto aos parâmetros estruturais de participação, as mudanças também não foram muito significativas, com pequena retração na parcela relativa do VBP e do VAB da indústria química nos totais da economia brasileira, para $15,1 \%$ e $16 \%$, respectivamente. A despeito das quedas mencionadas, a indústria química figurou ao longo de todo $\mathrm{o}$ período como uma das mais importantes da indústria de transformação brasileira. Em termos de participação no VAB total desta indústria, o consolidado do segmento químico apresenta a maior contribuição entre todas as demais atividades industriais. Quanto à participação no VBP, a indústria química fica atrás apenas da atividade produtora de alimentos e bebidas.

Chama atenção o alargamento da diferença entre o valor demandado de produtos químicos e o valor produzido dos mesmos. Vale dizer que esta diferença é basicamente composta pelos impostos indiretos, margens de comércio e transporte incidentes sobre os produtos químicos (IPI, ICMS, Imposto de importação, etc.), além das importações. Em 2000, da diferença de $\mathrm{R} \$ 57,8$ bilhões, $58,8 \%$ (R\$ 34 bilhões) correspondeu aos impostos indiretos e margens, enquanto $41,2 \%$ ou $\mathrm{R} \$ 23,8$ bilhões às importações. Em 2009, o percentual dos impostos e margens na diferença total entre o valor demandado e produzido ( $R \$ 169,8$ bilhões) foi ainda maior, de $64,3 \%$ ( $R \$ 109,1$ bilhões), enquanto as importações de químicos responderam por $35,7 \%$ ou $\mathrm{R} \$ 60,7$ bilhões. Não trataremos neste artigo do detalhamento dos tributos e das margens, sendo destacado apenas o crescimento do valor importado, o qual também foi bastante expressivo, média de $11 \%$ ao ano entre 2000 e 2009.

Tendo em vista a forte elevação do coeficiente de importação de produtos químicos e a baixa participação das exportações como destino final da produção interna, o saldo negativo na balança comercial do setor também apresentou com- 
portamento acelerado na década de 2000 . O saldo deficitário da balança do setor passou de US $\$ 6,6$ bilhões, em 2000, para US $\$ 15,7$ bilhões, em 2009, um ritmo de crescimento médio também de dois dígitos, de 10,1\% (ASSOCIAÇÃO BRASILEIRA DA INDÚSTRIA QUÍMICA, 2010b). Na pauta de importações, os principais segmentos são os produtos químicos orgânicos, inorgânicos e farmacêuticos. O principal produto químico importado diz respeito aos fertilizantes, cujo montante atingiu US\$ 3,9 bilhões ou 11,2 milhões de toneladas em 2009 (ASSOCIAÇÃO BRASILEIRA DA INDÚSTRIA QUÍMICA, 2010a).

Vale, por fim, ressaltar que o processo produtivo da indústria química é caracterizado, de forma geral, como de média-alta ou alta intensidade tecnológica, além de possuir participação considerável na geração de emprego do setor industrial. Em 2000, o pessoal ocupado na fabricação de produtos químicos correspondia a cerca de $6 \%$ do total da indústria de transformação, atribuindo ao setor o $5^{\circ}$ lugar no ranking nacional. No ano de 2009, por sua vez, essa participação caiu para 3,7\% (IBGE, 2009).

De acordo com Abdon et al. (2010), o setor químico está entre os grupos industriais mais complexos. Para chegar a essa conclusão, esses autores classificaram 5.107 produtos industriais de 124 países a partir das medidas de complexidade econômica de Hidalgo e Hausmann (2009). De forma geral, o grau de complexidade de um produto refere-se ao nível de ubiquidade e diversificação do mesmo em relação à quantidade de países que o exportam com vantagens comparativas. Desse modo, um país que tem sua estrutura produtiva mais diversificada, ou seja, produz uma maior variedade de bens é mais complexo do que um país que exporta poucos produtos. Por outro lado, uma mercadoria que é produzida por poucos países é mais complexa do que uma mercadoria que é exportada por muitos países (HIDALGO e HAUSMANN, 2009; ABDON et al., 2010; HAUSMANN et al., 2011).

Dado o elevado dinamismo do setor, em termos de seus avanços tecnológicos e elevada complexidade, os valores demandados de insumos químicos seguem representando componentes bastante importantes nos mais variados processos produtivos. Nas próximas seções, a importância dos insumos químicos nas diversas cadeias produtivas ficará ainda mais evidente, a partir das quais serão estimados os valores das importações indiretas destes insumos pela economia brasileira.

\section{A Utilização dos Dados de MP para a Estimação das Importações Indiretas}

Chamamos de MIP a base de dados na qual os fluxos (de oferta e demanda) que compõem o PIB de uma economia são apresentados de forma desagregada entre as atividades econômicas (GUILHOTO et al., 2010). Em outras palavras, se- 
gundo Miller e Blair (2009), a MIP representa uma fotografia da economia num determinado período de tempo.

Dois importantes fluxos monetários presentes em qualquer MIP correspondem aos valores de produção dos bens e serviços produzidos pelas atividades econômicas e aos valores de consumo intermediário de produtos demandados pelas atividades em seus respectivos processos produtivos. O VBP das atividades pode ser decomposto entre o total de Consumo Intermediário $(\mathrm{CI})$ a preços de mercado e o VAB das atividades. ${ }^{5}$ Com base na desagregação dos valores do CI entre os diferentes produtos que a estrutura da MIP apresenta, é possível estimar qual o peso relativo de um determinado insumo A sobre o valor de produção de uma atividade $\mathrm{B}$.

No entanto, conforme apontado na seção anterior, parte importante da demanda pelos produtos químicos, por exemplo, corresponde a impostos indiretos, margens de comércio e margens de transporte. Neste sentido, quando se trata do valor do $\mathrm{CI}$ a preços de mercado, e desejamos considerar apenas o valor referente à aquisição dos insumos químicos, torna-se necessário expurgar os valores dos impostos e margens. Tal separação só é possível a partir dos dados de uma MIP, nas quais são apresentados os dados de demanda (intermediária e final) nos chamados preços básicos. ${ }^{6}$ Assim, identificamos os valores especificamente destinados à aquisição dos insumos nacionais e estrangeiros.

Vale dizer que o cômputo de importações indiretas só faz sentido quando mensuradas para bens de uso predominantemente intermediário, ou seja, que se encontram, em grande medida, incorporados na produção de diversos outros bens e serviços finais ou mesmo em outros bens intermediários, tais como são os insumos da indústria química.

Em suma, a MIP serve ao cálculo de importações indiretas na medida em que apresenta a estrutura de CI (a preços básicos) e de produção das atividades econômicas. Proporemos dois métodos de estimação a partir da utilização dos dados de insumo-produto. O primeiro deles a partir do uso das próprias matrizes brasileiras, e outro baseado nos dados dos países de origem das importações, conforme apresentado nas próximas duas seções.

No caso do cálculo a partir dos dados de insumo-produto brasileiro serão utilizadas as duas últimas MIP oficiais de insumo-produto do Brasil calculadas pelo IBGE referente aos anos 2000 e 2005, além de uma matriz brasileira estimada a partir da metodologia de Moreira, Verges e Ribeiro (2014) e Martinez (2015), feita com base nos dados das Tabelas de Recursos e Usos (TRU) do IBGE para o ano de 2009. No cálculo alternativo a partir dos dados internacionais, serão utilizadas as

5 Dada a consolidação dos modelos de insumo-produto na literatura, o presente artigo não apresentará as equações tradicionais desta modelagem. Para mais detalhes, ver Miller e Blair (2009), Guilhoto et al. (2010), Moreira e Ribeiro (2013), entre outros.

6 Denominados como "preços na porta da fábrica", vide Feijó e Ramos (2008). 
MIP estimadas para diversos países que compõem o chamado World Input-Output Database (WIOD) (DIETZENBACHER et al., 2013) ) para os mesmos três anos supracitados.

\section{Estimativa das Importações Indiretas de Químicos a partir das MIP Brasileiras}

Nesta seção utilizaremos a estrutura da MIP nacional para o cálculo das importações indiretas de produtos químicos pela própria economia brasileira. Para tanto, utilizaremos como premissa básica a ideia de que a produção estrangeira importada pela economia brasileira tenha utilizado o mesmo percentual de insumos químicos em seus respectivos processos produtivos que os verificados nas atividades que operam no país. Antes de apresentarmos os resultados, vale mencionar alguns dos aspectos principais da MIP brasileira, bem como de que forma os produtos químicos estão contemplados.

Denota-se uma elevada diversificação das atividades da indústria química existente nas atuais MIP brasileiras. A referência em vigência do Sistema de Contas Nacionais utilizada pelo IBGE, tanto para a construção das TRU quanto para a MIP, corresponde à Classificação Nacional de Atividades Econômicas (CNAE), em sua versão 1.0. Vale lembrar que as últimas duas MIP oficiais, ancoradas na referida classificação de atividades, correspondem aos anos de 2000 e 2005.

Nestas matrizes, compostas por um total de 55 atividades produtivas, encontramos oito atividades consideradas neste trabalho como pertencentes ao denominado complexo da indústria química: "produtos químicos", "resinas e elastômeros", "farmacêuticos", "defensivos agrícolas", "perfumaria, higiene e limpeza", "tintas, vernizes, esmaltes e lacas", "produtos e preparados químicos diversos" e "artigos de borracha e plástico". Além das 55 atividades, a MIP brasileira na atual referência é composta por 110 produtos. Dentre aqueles pertencentes à indústria química, encontramos os mesmos nomes das atividades, com a diferença de duas desagregações, quais sejam: "produtos químicos" são desagregados em "produtos químicos orgânicos" e "produtos químicos inorgânicos" e os "artigos de borracha e plástico" em "artigos de borracha" e "artigos de plástico". Em outras palavras, existem dez produtos provenientes da indústria química. ${ }^{7}$

Já com relação ao terceiro ano da análise proposta, 2009, não existem tabelas de uma MIP oficial. Desse modo, foi estimada uma MIP a partir das TRU com base na metodologia proposta por Moreira, Verges e Ribeiro (2014) e Martinez (2015).

$7 \quad$ Vale ressaltar que tanto no produto quanto na atividade "Resinas e elastômeros" das matrizes brasileiras também estão comtemplados as fibras, fios, cabos e filamentos artificiais e sintéticos. 
De posse destas informações, é possível dimensionar para os três anos em análise os valores totais adquiridos de insumos da indústria química, tanto os de produção nacional como aqueles de origem estrangeira. Dividindo os valores desta demanda intermediária total pelo valor da produção de cada uma das atividades da matriz, estimam-se o conteúdo, em termos monetários, dos insumos químicos por unidade monetária de produção das atividades econômicas.

Do ponto de vista agregado, os dados das três matrizes mostram que no início da década passada, em 2000, o peso relativo dos insumos químicos no VBP total da economia brasileira era equivalente a 9,7\%. Em 2005, essa relação registrou $10,5 \%$ e no fim da década, em 2009 , caiu para $8,4 \%$.

Vale lembrar que existe discriminação de preços cobrados pelos insumos, a depender da atividade econômica demandante. Sendo assim, para expurgar os efeitos dos preços relativos seria necessário deflacionar todas as células das matrizes que representam a demanda por cada um dos insumos químicos de cada atividade. Na medida em que o objetivo principal deste trabalho é estimar o valor de produtos químicos, e não apenas as quantidades presentes no valor das importações brasileiras, trabalharemos com os valores a preços correntes de cada um dos anos analisados, sem nenhum procedimento de deflação.

Um desdobramento interessante da aplicação deste método e que vale a pena destacar refere-se à decomposição do valor contido de químicos no valor de produção das atividades brasileiras em insumos nacionais e importados. Considerando o valor total de insumos químicos na produção agregada da economia brasileira, denota-se queda na participação dos importados na primeira metade da década, seguida de uma aceleração na segunda metade da década. Em termos agregados, no ano de 2000, os insumos químicos importados representavam $10 \%$ do CI total de químicos. Em 2005, esse mesmo percentual caiu para 9,2\% e em 2009 , voltou a crescer, atingindo $10,7 \%$.

Na comparação com o VBP das atividades, a Tabela 1 traz a separação dos percentuais do total de insumos químicos em nacionais e importados. 
Tabela 1 - Participação relativa de químicos no valor bruto da produção (VBP) das atividades brasileiras desagregada em doméstico ou importado - 2000, 2005 e 2009

\begin{tabular}{|c|c|c|c|c|c|c|}
\hline \multirow{2}{*}{ Setor } & \multicolumn{2}{|c|}{2000} & \multicolumn{2}{|c|}{2005} & \multicolumn{2}{|c|}{2009} \\
\hline & Dom. & Imp. & Dom. & Imp. & Dom. & Imp. \\
\hline Agricultura, silvicultura, exploração florestal & $14,2 \%$ & $1,4 \%$ & $17,5 \%$ & $1,1 \%$ & $16,0 \%$ & $1,4 \%$ \\
\hline Pecuária e pesca & $5,3 \%$ & $0,20 \%$ & $5,5 \%$ & $0,2 \%$ & $5,1 \%$ & $0,19 \%$ \\
\hline Petróleo e gás natural & \1,4\% & $0,7 \%$ & $\mid 1,3 \%$ & $0,5 \%$ & $\mid 1,0 \%$ & $0,5 \%$ \\
\hline Minério de ferro & \0,8\% & $0,2 \%$ & $\mid 1,0 \%$ & $0,1 \%$ & $\mid 0,7 \%$ & $0,1 \%$ \\
\hline Outros da indústria extrativa & $5,9 \%$ & $0,9 \%$ & $6,5 \%$ & $1,0 \%$ & $5,9 \%$ & $1,0 \%$ \\
\hline Alimentos e bebidas & \3,0\% & $0,4 \%$ & $\mid 2,5 \%$ & $0,3 \%$ & $\mid 2,2 \%$ & $0,3 \%$ \\
\hline Produtos do fumo & \1,3\% & $0,3 \%$ & $\mid 1,1 \%$ & $0,3 \%$ & $\mid 0,7 \%$ & $0,2 \%$ \\
\hline Têxteis & $6,7 \%$ & $3,4 \%$ & $6,6 \%$ & $2,8 \%$ & $5,3 \%$ & $3,0 \%$ \\
\hline Artigos do vestuário e acessórios & \1,0\% & $0,2 \%$ & $\mid 0,8 \%$ & $0,2 \%$ & $\mid 0,7 \%$ & $0,2 \%$ \\
\hline Artefatos de couro e calçados & $8,7 \%$ & $3,1 \%$ & $7,6 \%$ & $2,9 \%$ & $6,8 \%$ & $3,3 \%$ \\
\hline Produtos de madeira - exclusive móveis & $3,2 \%$ & $0,7 \%$ & $\mid 3,4 \%$ & $0,8 \%$ & $\mid 2,6 \%$ & $0,8 \%$ \\
\hline Celulose e produtos de papel & $6,9 \%$ & $1,5 \%$ & $8,8 \%$ & $1,8 \%$ & $7,2 \%$ & $1,8 \%$ \\
\hline Jornais, revistas, discos & $7,6 \%$ & $1,8 \%$ & $8,3 \%$ & $2,0 \%$ & $6,7 \%$ & $1,7 \%$ \\
\hline Refino de petróleo e coque & $0,7 \%$ & $0,2 \%$ & $\mid 1,1 \%$ & $0,3 \%$ & $|0,8 \%|$ & $0,2 \%$ \\
\hline Álcool & $\mid 1,7 \%$ & $0,1 \%$ & $\mid 1,4 \%$ & $0,1 \%$ & $\mid 1,2 \%$ & $0,1 \%$ \\
\hline Produtos químicos & $12,2 \%$ & $10,3 \%$ & $12,9 \%$ & $8,8 \%$ & $10,8 \%$ & $9,5 \%$ \\
\hline Fabricação de resina e elastômeros & $50,2 \%$ & $5,7 \%$ & $46,3 \%$ & $5,8 \%$ & $43,3 \%$ & $7,7 \%$ \\
\hline Produtos farmacêuticos & $6,1 \%$ & $11,1 \%$ & $7,4 \%$ & $10,0 \%$ & $6,5 \%$ & $8,0 \%$ \\
\hline Defensivos agrícolas & $30,4 \%$ & $11,8 \%$ & $28,9 \%$ & $13,5 \%$ & $24,9 \%$ & $15,6 \%$ \\
\hline Perfumaria, higiene e limpeza & $20,4 \%$ & $5,5 \%$ & $22,7 \%$ & $5,4 \%$ & $19,1 \%$ & $5,6 \%$ \\
\hline Tintas, vernizes, esmaltes e lacas & $18,2 \%$ & $15,8 \%$ & $19,9 \%$ & $14,7 \%$ & $14,0 \%$ & $13,8 \%$ \\
\hline Produtos e preparados químicos diversos & $20,5 \%$ & $13,9 \%$ & $22,3 \%$ & $14,5 \%$ & $17,1 \%$ & $15,2 \%$ \\
\hline Artigos de borracha e plástico & $34,0 \%$ & $8,6 \%$ & $34,0 \%$ & $7,6 \%$ & $26,8 \%$ & $8,1 \%$ \\
\hline Cimento & $2,3 \%$ & $0,7 \%$ & $2,8 \%$ & $0,7 \%$ & $\mid 2,7 \%$ & $0,8 \%$ \\
\hline Outros produtos de minerais não-metálicos & $6,0 \%$ & $1,4 \%$ & $5,4 \%$ & $1,7 \%$ & $\mid 3,5 \%$ & $1,5 \%$ \\
\hline Fabricação de aço e derivados & $4,3 \%$ & $1,8 \%$ & $4,3 \%$ & $1,5 \%$ & $\mid 2,9 \%$ & $1,3 \%$ \\
\hline Metalurgia de metais não-ferrosos & $6,3 \%$ & $1,2 \%$ & $6,9 \%$ & $1,4 \%$ & $5,8 \%$ & $1,4 \%$ \\
\hline Produtos de metal - exclusive máquinas e equipamentos & $7,5 \%$ & $1,6 \%$ & $7,1 \%$ & $1,3 \%$ & $5,6 \%$ & $1,3 \%$ \\
\hline
\end{tabular}




\section{Setor}

2000

2005

2009

Máquinas e equipamentos, inclusive manutenção e reparos Eletrodomésticos

Dom. Imp. Dom. Imp. Dom. Imp.

Máquinas para escritório e equipamentos de informática

Máquinas, aparelhos e materiais elétricos

Material eletrônico e equipamentos de comunicações

Aparelhos/instrumentos médico-hospitalar, medida e óptico

Automóveis, camionetas e utilitários

Caminhões e ônibus

Peças e acessórios para veículos automotores

Outros equipamentos de transporte

Móveis e produtos das indústrias diversas

Eletricidade e gás, água, esgoto e limpeza urbana

Construção

Comércio

Transporte, armazenagem e correio

Serviços de informação

Intermediação financeira e seguros

Serviços imobiliários e aluguel

Serviços de manutenção e reparação

Serviços de alojamento e alimentação

Serviços prestados às empresas

Educação mercantil

Saúde mercantil

Outros serviços

Educação pública

Saúde pública

Administração pública e seguridade social

\begin{tabular}{|l|l|l|l||l|l|}
\hline $4,1 \%$ & $0,5 \%$ & $4,7 \%$ & $0,6 \%$ & $3,7 \%$ & $0,5 \%$
\end{tabular}

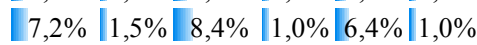

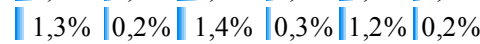

| $6,6 \% \mid 2,5 \%$ | $7,1 \%$ | $1,5 \%$ |4,9\%】1,4\%

| $2,\left.2 \%\right|_{0,6 \%}|3,3 \%|_{0,4 \%}|2,8 \%|_{0,4 \%}$

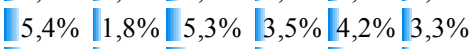

\begin{tabular}{|l|l|l|l|l|l|l|}
\hline & $7,0 \%$ & $\mid 1,6 \%$ & $8,4 \%$ & $\mid 1,8 \%$ & $7,1 \% \mid 1,6 \%$
\end{tabular}

\begin{tabular}{|l|l|l|l|l|l|l|l|}
\hline $5,0 \%$ & $\mid 1,6 \%$ & $6,5 \%$ & $2,9 \%$ & $4,8 \%$ & $\mid 2,2 \%$
\end{tabular}

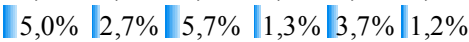

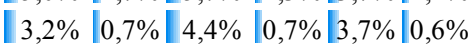

10,9\% $\mid 2,0 \%$ - $10,5 \%$ |1,7\% $8,5 \% \rrbracket 1,8 \%$

| 1,3\% |0,2\% \1,2\% |0,2\% |1,2\%|0,2\%

| $4,\left.\left.8 \%\right|_{0,5 \%}\left\|\left._{4,6 \%}\right|_{0,4 \%}\right\|_{4,2} \%\right|_{0,4 \%}$

| $0,\left.6 \%\right|_{0,0 \%} \|\left.\left.\left._{0,7 \%}\right|_{0,0 \%}\right|_{0,5 \%}\right|_{0,0 \%}$

| $1,\left.7 \%\right|_{0,1 \%} \|\left.\left.\left._{1,9 \%}\right|_{0,1 \%}\right|_{1,6 \%}\right|_{0,1 \%}$

| $0,8 \%|0,0 \% \rrbracket 1,5 \%|_{0,1 \%}|1,6 \%| 0,1 \%$

| $0,\left.\left.\left.\left.\left.1 \%\right|_{0,0 \%}\right|_{0,1 \%}\right|_{0,0 \%}\right|_{0,1 \%}\right|_{0,0 \%}$

| $0,1 \%|0,0 \%| 0,1 \%|0,0 \%| 0,1 \% \mid 0,0 \%$

| $0,\left.\left.9 \%\right|_{0,1 \%} \rrbracket_{0,8 \%}\right|_{0,1 \%}|0,7 \%|_{0,1 \%}$

\ $1,\left.1 \%\right|_{0,0 \% \rrbracket} 0,\left.\left.\left.8 \%\right|_{0,0 \%}\right|_{0,7 \%}\right|_{0,0 \%}$

| $0,\left.\left.9 \%\right|_{0,1 \%} \rrbracket_{1,6 \%}\right|_{0,1 \%} \|\left._{1,7 \%}\right|_{0,1 \%}$

| $0,\left.8 \%\right|_{0,1 \%} \|\left.\left._{1,0 \%}\right|_{0,2 \%}\right|_{0,9 \%} \mid 0,1 \%$

\begin{tabular}{|l||l|l|l|l|}
\hline $7,4 \%$ & $0,5 \%$ & $9,8 \%$ & $0,8 \%$ & $8,1 \%$
\end{tabular} \mid 0,$6 \%$

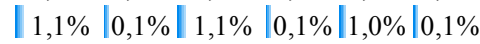

| $0,3 \% \mid 0,1 \%$ | $0,\left.\left.\left.4 \%\right|_{0,1 \%}\right|_{0,5 \%}\right|_{0,1 \%}$

| $9,2 \%$ | $2,6 \%|8,1 \% \quad 3,2 \%| 1,6 \% \mid 4,3 \%$

| $0,\left.7 \%\left\|\left._{0,1 \%} \rrbracket_{0,8 \%}\right|_{0,1 \%}\right\|_{0,5 \%}\right|_{0,1 \%}$

Fonte: Elaboração própria com base nos dados do IBGE.

Na comparação entre os dados de 2000 e 2009, das seis atividades cujos percentuais de insumos químicos na composição de seus respectivos VBP apresentam os valores mais significativos, quatro delas apresentaram queda no valor percentual de insumos químicos ao mesmo tempo em que o peso relativo dos insumos químicos importados no próprio VBP das atividades aumentou. São os casos de "Resinas e elastômeros", "Defensivos agrícolas", "Perfumaria, higiene e limpeza" e "Produtos e preparados químicos diversos". Além destas quatro atividades, estiveram nesta mesma situação outras onze. É razoável supor que nestas onze atividades tenha ocorrido um processo de substituição de insumos químicos produzidos no país por insumos químicos com origem no exterior.

Em outros casos verifica-se que, a despeito da queda na parcela relativa de insumos químicos importados no VBP no período 2000-2009, a queda registrada 
no percentual total de insumos químicos é maior. Nestes, há também indícios de substituição de insumos químicos nacionais por importados. Nesta última situação estão enquadradas outras importantes atividades demandantes de insumos químicos, tais como: "Produtos químicos", "Tintas, vernizes, esmaltes e lacas", "Artigos de borracha e plástico", "Móveis e produtos das indústrias diversas" e outras quinze atividades, totalizando dezenove. Em alguns poucos casos houve aumento do percentual total de insumos químicos no VBP que, no entanto, se deu em magnitude inferior à variação positiva do peso relativo dos insumos químicos importados. Nesta situação estão apenas quatro atividades da matriz, quais sejam: "Outras da indústria extrativa", "Aparelhos/instrumentos médico-hospitalar, medida e óptico", "Caminhões e ônibus" e "Serviços imobiliários e aluguéis".

Em suma, na etapa de construção dos vetores de conteúdo de insumos químicos no VBP das atividades da matriz, necessária ao cálculo das importações indiretas, com uma simples desagregação entre insumos nacionais e importados, é possível perceber aumento da importância relativa do valor importado de químicos nas cadeias produtivas da maioria das atividades econômicas brasileiras. Contudo, não se pode de antemão concluir que estes resultados correspondem necessariamente a um processo generalizado de substituição de produtos químicos de origem nacional por importada. Para tanto, precisaríamos de uma análise mais detalhada acerca das mudanças nos preços relativos, tanto entre preços internos e internacionais dos próprios insumos químicos, quanto destes em relação aos demais preços setoriais, para afirmações mais precisas sobre em quais segmentos o processo de substituição ocorreu efetivamente. De todo modo, a evolução dos referidos percentuais representa forte indício de que a substituição tenha ocorrido na maioria dos segmentos, em linha com os argumentos que apontam para um processo de desindustrialização ocorrido na economia brasileira neste período (BRESSER PEREIRA, 2007; BRESSER PEREIRA; GALA, 2010).

Finalmente, para o cálculo das importações indiretas de químicos, utiliza-se inicialmente um vetor $q$ de dimensão 55x1 composto pelos coeficientes de participação dos insumos químicos $i$ demandados pelas $j$ atividades econômicas $\left(u_{i j}\right)$ no VBP destas mesmas atividades $\left(x_{j}\right)$, de modo que:

$$
q_{j}=\frac{u_{i j}}{x j}
$$

Na sequência, utilizamos a matriz Market-share (M) para transformarmos as importações diretas totais desagregadas, inicialmente por produto (IDp), em importações por atividade econômica. O valor das importações indiretas de químicos (IIq)é obtido a partir da equação 2 . 


$$
\mathrm{II}_{\mathrm{q}}=\hat{\mathrm{q}} *\left(\mathrm{M} * \mathrm{ID}_{\mathrm{p}}\right)
$$

Em que:

Ilq é um vetor de dimensão 55x1;

q é um vetor diagonalizado amatriz diagonal de dimensão 55x55;

$M$ é uma matriz de dimensão $55 \times 110$;

IDp é um vetor de dimensão 110x1.

A Tabela 2 apresenta o resultado dos valores de importações diretas e a estimativas para as importações indiretas de insumos químicos por atividade econômica.

Tabela 2 - Estimativas das importações diretas totais e indiretas de insumos químicos - valores em $\mathrm{R} \$$ milhões

\begin{tabular}{|c|c|c|c|c|c|c|}
\hline \multirow{2}{*}{ Setores } & \multicolumn{2}{|c|}{2000} & \multicolumn{2}{|c|}{2005} & \multicolumn{2}{|c|}{2009} \\
\hline & Diretas & Indiretas & Diretas & Indiretas & Diretas & Indiretas \\
\hline Agricultura, silvicultura, exploração florestal & 3.686 & 574 & 4.676 & 871 & 6.625 & 1.148 \\
\hline Pecuária e pesca & 420 & 23 & 415 & 24 & 751 & 40 \\
\hline Petróleo e gás natural & 8.764 & 178 & 20.775 & 364 & 21.636 & 317 \\
\hline Minério de ferro & 3 & 0 & 83 & 1 & 71 & 1 \\
\hline Outros da indústria extrativa & 2.624 & 179 & 7.622 & 570 & 10.404 & 717 \\
\hline Alimentos e bebidas & 3.926 & 130 & 5.155 & 144 & 9.054 & 228 \\
\hline Produtos do fumo & 1.355 & 21 & 1.984 & 27 & 4.142 & 37 \\
\hline Têxteis & 1.793 & 181 & 2.339 & 218 & 4.418 & 370 \\
\hline Artigos do vestuário e acessórios & 288 & 3 & 607 & 6 & 1.607 & 14 \\
\hline Artefatos de couro e calçados & 508 & 60 & 785 & 82 & 1.384 & 140 \\
\hline Produtos de madeira - exclusive móveis & 176 & 7 & 232 & 10 & 266 & 9 \\
\hline Celulose e produtos de papel & 1.929 & 162 & 2.326 & 248 & 2.916 & 262 \\
\hline Jornais, revistas, discos & 511 & 48 & 379 & 39 & 471 & 40 \\
\hline Refino de petróleo e coque & 6.232 & 58 & 11.068 & 149 & 14.227 & 150 \\
\hline Álcool & 24 & 0 & 5 & 0 & 20 & 0 \\
\hline Produtos químicos & 7.632 & 1.718 & 15.595 & 3.373 & 20.237 & 4.118 \\
\hline Fabricação de resina e elastômeros & 3.457 & 1.934 & 6.188 & 3.226 & 7.597 & 3.875 \\
\hline Produtos farmacêuticos & 3.864 & 663 & 8.023 & 1.394 & 11.445 & 1.651 \\
\hline Defensivos agrícolas & 1.199 & 506 & 2.399 & 1.018 & 4.206 & 1.706 \\
\hline Perfumaria, higiene e limpeza & 2.607 & 676 & 3.794 & 1.064 & 5.058 & 1.251 \\
\hline Tintas, vernizes, esmaltes e lacas & 505 & 171 & 605 & 209 & 769 & 214 \\
\hline Produtos e preparados químicos diversos & 1.946 & 670 & 2.863 & 1.053 & 3.837 & 1.238 \\
\hline Artigos de borracha e plástico & 2.710 & 1.155 & 5.230 & 2.175 & 7.073 & 2.468 \\
\hline Cimento & 70 & 2 & 88 & 3 & 226 & 8 \\
\hline Outros produtos de minerais não-metálicos & 995 & 74 & 1.569 & 112 & 2.131 & 106 \\
\hline Fabricação de aço e derivados & 1.510 & 92 & 3.844 & 222 & 7.060 & 297 \\
\hline Metalurgia de metais não-ferrosos & 2.308 & 174 & 4.836 & 398 & 5.319 & 382 \\
\hline Produtos de metal - exclusive máquinas e equipamentos & 1.512 & 139 & 3.241 & 270 & 5.529 & 385 \\
\hline
\end{tabular}

continua.. 


\begin{tabular}{|c|c|c|c|c|c|c|}
\hline \multirow{2}{*}{ Setores } & \multirow{2}{*}{\multicolumn{2}{|c|}{$\begin{array}{c}2000 \\
\text { Diretas Indiretas }\end{array}$}} & \multicolumn{2}{|c|}{2005} & \multicolumn{2}{|c|}{2009} \\
\hline & & & Diretas & Indiretas & Diretas & Indiretas \\
\hline Máquinas e equipamentos, inclusive manutenção e reparos & 9.623 & 446 & 18.318 & 963 & 28.260 & 1.193 \\
\hline Eletrodomésticos & 328 & 28 & 460 & 44 & 1.133 & 83 \\
\hline Máquinas para escritório e equipamentos de informática & 4.392 & 66 & 5.949 & 98 & 9.398 & 135 \\
\hline Máquinas, aparelhos e materiais elétricos & 4.819 & 437 & 6.794 & 589 & 10.416 & 647 \\
\hline Material eletrônico e equipamentos de comunicações & 12.747 & 363 & 18.637 & 686 & 22.184 & 690 \\
\hline Aparelhos/instrumentos médico-hospitalar, medida e óptico & 4.239 & 304 & 8.290 & 732 & 11.408 & 860 \\
\hline Automóveis, camionetas e utilitários & 4.145 & 359 & 4.071 & 415 & 13.822 & 1.203 \\
\hline Caminhões e ônibus & 715 & 47 & 1.063 & 100 & 1.610 & 113 \\
\hline Peças e acessórios para veículos automotores & 4.164 & 318 & 9.112 & 641 & 10.605 & 521 \\
\hline Outros equipamentos de transporte & 3.767 & 145 & 5.910 & 301 & 10.865 & 468 \\
\hline Móveis e produtos das indústrias diversas & 995 & 128 & 1.295 & 158 & 2.253 & 231 \\
\hline Eletricidade e gás, água, esgoto e limpeza urbana & 1.798 & 27 & 2.771 & 39 & 3.101 & 43 \\
\hline Construção & 145 & 8 & 354 & 18 & 719 & 33 \\
\hline Comércio & 963 & 6 & 2.532 & 18 & 2.452 & 14 \\
\hline Transporte, armazenagem e correio & 1.864 & 34 & 3.764 & 74 & 6.004 & 104 \\
\hline Serviços de informação & 2.708 & 24 & 5.441 & 87 & 7.561 & 127 \\
\hline Intermediação financeira e seguros & 1.391 & 2 & 3.612 & 4 & 5.965 & 4 \\
\hline Serviços imobiliários e aluguel & 2.242 & 3 & 8.660 & 11 & 15.662 & 22 \\
\hline Serviços de manutenção e reparação & 6 & 0 & 8 & 0 & 41 & 0 \\
\hline Serviços de alojamento e alimentação & 7.152 & 80 & 8.089 & 69 & 15.601 & 112 \\
\hline Serviços prestados às empresas & 6.139 & 61 & 11.108 & 184 & 16.977 & 306 \\
\hline Educação mercantil & 295 & 3 & 754 & 9 & 655 & 7 \\
\hline Saúde mercantil & 165 & 13 & 566 & 60 & 923 & 80 \\
\hline Outros serviços & 763 & 9 & 2.524 & 29 & 3.973 & 42 \\
\hline Educação pública & 15 & 0 & 25 & 0 & 43 & 0 \\
\hline Saúde pública & 6 & 1 & 3 & 0 & 2 & 0 \\
\hline Administração pública e seguridade social & 355 & 3 & 524 & 5 & 737 & 4 \\
\hline Total & 62.552 & 9.598 & 116.727 & 17.268 & 158.478 & 21.172 \\
\hline
\end{tabular}

Fonte: Elaboração própria com base nos dados do IBGE.

Calculando as taxas de crescimento médias anuais de 2000 a 2009 para os valores (nominais) das duas colunas da Tabela 2, chegamos aos seguintes resultados: as importações diretas totais cresceram nominalmente a um ritmo anual médio de $11,9 \%$ no referido período, enquanto as importações indiretas de químicos registraram expansão média nominal de $9,5 \%$ ao ano.

Fazendo um recorte temporal em 2005, dividindo o período em dois, denotam-se ritmos distintos de crescimento tanto do valor total importado (em $\mathrm{R} \$$ ) quanto do valor das importações indiretas de químicos. Entre 2000 e 2005, verifica-se uma taxa média de crescimento nominal (em $\mathrm{R} \$$ ) de 12,3\% ao ano. Quanto às importações indiretas, neste mesmo período, a expansão se deu a um ritmo médio anual de 12,6\%. Já entre 2005 e 2009, as taxas nominais de crescimento foram menores. Neste último intervalo, o valor total importado cresceu, em termos diretos e nominais (em $\mathrm{R} \$$ ), a um ritmo de 9,9\% ao ano. Já o crescimento médio nominal das importações indiretas de químicos foi de 5,7\% ao ano. 
Sobre estas taxas, vale ressaltar dois aspectos importantes que devem ser considerados. O primeiro deles diz respeito ao impacto da taxa de câmbio sobre estes resultados, uma vez que as importações são cotadas em dólares e transformadas em reais com base no câmbio médio anual (média das taxas de câmbio mensais). Se na primeira metade da década a predominância de uma dinâmica de desvalorização cambial elevou os preços dos importados, na segunda metade o preço dos importados foi afetado negativamente, conforme apontado no Gráfico1.

Gráfico 1 - Taxa de câmbio nominal ${ }^{8}(\mathrm{R} \$ / \mathrm{US} \$)$

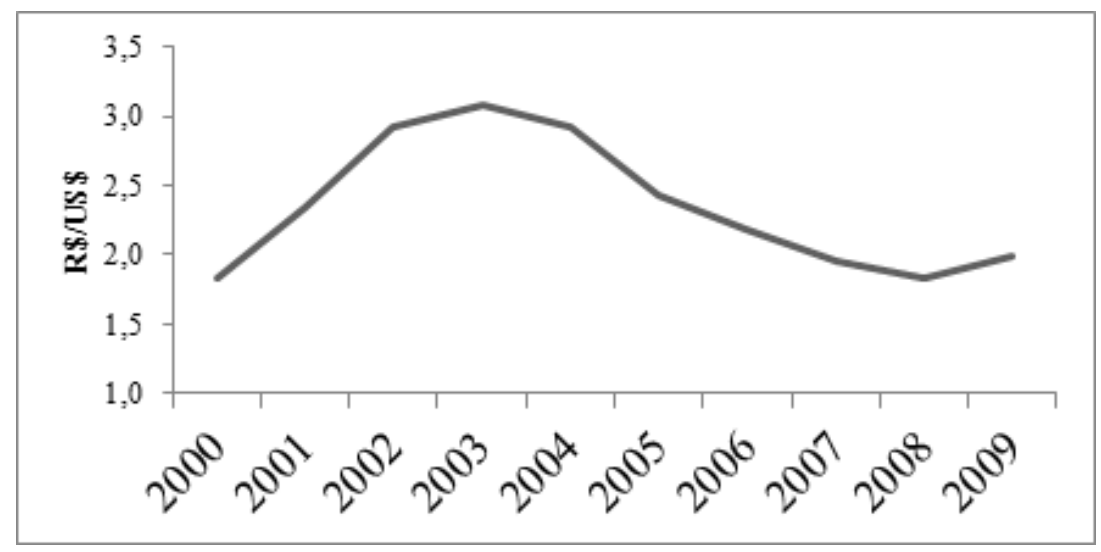

Fonte: Elaboração própria a partir de dados do Banco Central.

Sendo assim, na primeira metade da década o câmbio contribuiu para inflar a taxa de crescimento das importações, enquanto na segunda atuou no sentido de reduzir o valor das importações. Considerando que os movimentos do câmbio na comparação das duas metades da década foram de magnitude similar, porém em direções opostas, pode-se dizer que a taxa de crescimento apresentada das importações entre 2000 e 2009 (11,3\%) foi predominantemente determinada pelas mudanças dos preços internacionais (em US\$) e pelo quantum (volume) dos produtos importados.

Com base nos dados da Funcex, o volume de importações no período 20002009 apresentou expansão de 4,6\%, enquanto os preços (em US\$) registraram crescimento de $4,8 \%$, totalizando $9,4 \%$. A explicação da diferença entre esta última taxa e a taxa de crescimento nominal das importações totais entre 2000 e 2009 (11,9\%), ou seja, $2,5 \%$, pode ser atribuída a um câmbio ligeiramente mais desvalorizado em 2009 em comparação ao nível de 2000.

Fazendo a mesma divisão nos dois intervalos referidos anteriormente para os índices de volume e preço das importações diretas totais, denotam-se com-

8 Médias anuais das taxas médias de câmbio PTAX de compra e venda. 
portamentos distintos. No que se refere aos preços dos produtos estrangeiros, na primeira metade da década dos anos 2000 o crescimento foi de 4,0\%, enquanto na segunda metade, até 2009, a expansão nos preços foi de 5,8\% ao ano. Quanto aos volumes de importação, de 2000 a 2005, o crescimento foi de apenas 1,7\% a.a., ao passo que de 2005 a 2009, a expansão do quantum importado foi de 5,8\% a.a.

Podemos inferir que a menor taxa de crescimento nominal em $\mathrm{R} \$$ das importações indiretas de químicos no período de 2005 a 2009 em relação ao verificado na primeira década não implica necessariamente queda no ritmo de expansão dos valores nominais em dólares, ${ }^{9}$ tampouco do volume dos insumos químicos indiretamente importados. Além disso, é interessante notar o surgimento de uma diferença significativa entre as taxas nominais de crescimento dos valores totais de importação e da estimativa das importações indiretas na segunda metade da década. Pode-se dizer que o menor ritmo de crescimento do valor das importações indiretas de químicos em $\mathrm{R} \$$ é reflexo do aumento da parcela importada na demanda total por estes insumos, o que elevou o impacto da valorização do câmbio na segunda metade da década no cômputo do crescimento nominal medido na moeda brasileira.

O segundo aspecto diz respeito ao fato de que no ano de 2009 a economia brasileira foi afetada de forma mais significativa pela crise financeira internacional eclodida nos Estados Unidos em 2008, quando houve retração anual real de 0,3\% no PIB brasileiro (CARVALHO, 2008; FERRARI FILHO; PAULA, 2008). Além disso, houve queda generalizada nos preços internacionais e redução dos volumes importados. Dessa forma, caso não tivesse havido tais efeitos externos negativos neste ano em particular, as taxas nominais de crescimento seriam certamente maiores.

Enfim, sabemos que a hipótese assumida de homogeneidade nos processos produtivos/tecnológicos, além da estrutura de preços relativos, dos países de origem das importações, pode levar a sérias distorções dos resultados obtidos para as importações indiretas. Por este motivo, na próxima seção faremos nova estimativa das importações indiretas de químicos, a partir das MIP dos principais países que exportam para o Brasil para, posteriormente, realizarmos uma análise comparativa dos resultados.

\section{Estimativa das Importações Indiretas baseadas nas MIP Internacionais}

Nesta seção, baseado no mesmo procedimento descrito na seção anterior, apresentaremos uma estimativa de importações indiretas de produtos químicos buscando levar em conta a diversificação da estrutura produtiva/tecnológica e de preços relativos encontrada nos países de origem das importações totais brasi-

9 Com a metodologia que faz uso das matrizes internacionais, o valor das importações indiretas será inicialmente estimado em dólar. 
leiras. Para tanto, utilizamos uma base de dados do chamado World Input-Output Database (WIOD), que compila informações estatísticas harmonizadas para 39 países e uma região denominada de "Resto do Mundo", sendo coordenada pela Comissão Europeia.

As matrizes nacionais do WIOD são compostas por 35 atividades, apresentando fluxos de produção, importação, demanda intermediária intersetorial e de demanda final mensurados em dólares correntes a preços básicos no período de 1995 a 2011 , sendo realizadas estimativas de importações indiretas apenas para os anos de 2000, 2005 e 2009.

Encontramos apenas duas atividades pertencentes à indústria química nestas matrizes, quais sejam: "Chemicals and chemical products" e "Rubber and plastics". Com base no tradutor do ISIC rev. 3, denota-se que a primeira atividade é composta por três grandes grupos: químicos básicos (composto pelos químicos orgânicos, inorgânicos, resinas e elastômeros); outros produtos químicos (composto por "defensivos agrícolas", "tintas, vernizes, esmaltes e lacas", "farmacêuticos", "perfumaria, higiene e limpeza" e "outros químicos"); e, por fim, fibras sintéticas e artificiais. Quanto à atividade "Rubber and Plastics", as atividades nela contidas correspondem à própria tradução literal, ou seja, é composta pela produção de borracha e plástico.

Estas duas atividades, portanto, correspondem ao complexo da indústria química a ser focado na estimativa, que apresenta total compatibilidade com as oito atividades (ou dez produtos) representantes da indústria química na matriz brasileira. ${ }^{10}$

A tradução das atividades entre as matrizes não é direta e requer bastante atenção aos detalhes. De todo modo, as informações são certamente comparáveis, uma vez que os dados de oferta e demanda das matrizes nacionais, conforme colocado pela metodologia de construção do WIOD, basearam-se nos próprios fluxos das TRU de cada um dos países. Contudo, as técnicas de ajuste necessárias para o balanceamento entre os fluxos de oferta e demanda, envolvendo todos os países no caso WIOD, acabam alterando os dados primários. ${ }^{11}$ No entanto, fazendo uma análise comparativa entre os fluxos de importação em $R \$$ das matrizes do IBGE e de importação das matrizes do WIOD (convertidos em R $\$$ por meio do câmbio anual médio), denotam-se diferenças pequenas. Para os três anos em análise, a diferença entre o total importado pela economia brasileira nas matrizes da Comissão Europeia e do IBGE foi, no máximo, de 6,5\%, registrada em 2009. Para

$10 \quad$ No Anexo 1 todas as atividades das matrizes do WIOD podem ser visualizadas, assim como a correspondência destas com as atividades das matrizes brasileiras do IBGE, construída a partir do tradutor, disponível em < http://concla.ibge.gov.br/images/concla/documentacao/CIIUxCNAE. pdf $>$.

11 Tradicionalmente, a técnica de ajuste mais utilizada para o balanceamento de MIP é o RAS. Para mais detalhe, ver Miller e Blair (2009, p. 313). 
2000, 2005 e 2009 os fluxos de importação apresentados pelo IBGE foram ligeiramente superiores aos apresentados nas matrizes do WIOD. A Tabela 3 sumariza os valores (já convertidos para $\mathrm{R} \$$ ) de importações brasileiras apurados por estas duas fontes.

Tabela 3 - Valores das importações brasileiras (em milhões $R \$$ )

\begin{tabular}{l|l|c|c|c}
\hline \multirow{2}{*}{ Importações de bens e serviços } & Fonte & $\mathbf{2 0 0 0}$ & $\mathbf{2 0 0 5}$ & $\mathbf{2 0 0 9}$ \\
\cline { 2 - 5 } & & & & \\
\cline { 2 - 5 } & WIOD & 130.735 & 235.744 & 337.543 \\
& IBGE & 138.492 & 247.362 & 360.847 \\
\hline
\end{tabular}

Fonte: Elaboração própria com base nos dados do IBGE e da WIOD.

Uma das principais vantagens da base do WIOD em relação às MIP tradicionais diz respeito à desagregação das importações não apenas por atividade econômica, mas também por país de origem. Dessa forma, torna-se possível o cruzamento das importações por atividade econômica com seus respectivos países de origem.

Neste caso, para o cálculo das importações indiretas totais dos insumos químicos temos disponível além do valor dos insumos químicos (i) demandados por cada atividade (j), informações sobre cada país de origem (z) das importações brasileiras, ou seja, temos uma dimensão adicional em relação ao cálculo anterior. Assim, podemos reescrever os elementos da matriz de coeficientes de insumos químicos no VBP das atividades econômicas de cada país que exporta para o Brasil $\left(x_{j 2}\right)$ da seguinte forma:

$$
Q_{j z}=\frac{u_{i j z}}{x j z}
$$

Portanto, a matriz $Q$ deixa de ser um vetor diagonalizado ou uma matriz diagonal. Nas linhas inserimos os coeficientes de participação dos insumos químicos no VBP das atividades econômicas de um mesmo país. Nas colunas temos os mesmos coeficientes para uma mesma atividade nos diferentes países. As importações brasileiras diretas (ID) também deixam de ser representadas por um vetor, ${ }^{12}$ passando a compor uma matriz, na qual os elementos nas linhas correspondem ao valor importado de uma mesma atividade dos diversos países. Nas colunas temos os valores de importação de um mesmo país desagregada por atividade. Por fim, as importações indiretas $\left(\mathrm{II}_{q}\right)$ são calculadas da seguinte forma:

12 Vale dizer que a base da WIOD já é apresentada na estrutura atividade $\mathrm{x}$ atividade, não sendo necessário utilizar a matriz Market-share para a transformação das importações por produto em importações por atividade, como feito na estimativa anterior (vide equação 2). 
Em que:

$$
\mathrm{II}_{\mathrm{q}}=\mathrm{Q} * \mathrm{ID}
$$

Q é uma matriz de dimensão 40×35;

ID é uma matriz de dimensão $35 \times 40$.

O resultado da equação 4 corresponde a uma matriz diagonal de dimensão 40x40. Sendo assim, os elementos correspondem aos valores de importações indiretas de químicos por país. O traço da matriz equivale às importações indiretas totais de insumos químicos pela economia brasileira. Vale dizer que o cálculo poderia ser feito de forma distinta, invertendo as atividades e os países nas linhas e colunas. Dessa forma alternativa, obteríamos também como resultado final uma matriz diagonal, mas de dimensão 35×35, na qual os elementos corresponderiam aos valores de importações indiretas de insumos químicos por atividade econômica, já consolidando as diferentes origens das importações diretas. De todo modo, o traço desta matriz resultaria no mesmo valor do traço da matriz apresentada, ou seja, o total das importações indiretas de insumos químicos seria o mesmo.

Dito isso, trataremos inicialmente das mudanças ocorridas entre os principais parceiros comerciais brasileiros do ponto de vista das importações. Em seguida, com base nestas mudanças, abordaremos as principais modificações nos percentuais de insumos químicos da produção estrangeira presente na economia brasileira.

A Tabela 4 apresenta os fluxos de importações brasileiras apresentados pelo WIOD (em US\$), bem como o peso relativo na pauta importadora de cada um dos países considerados nesta base de dados. 
Tabela 4 - Fluxos totais de importações brasileiras por origem - 2000, 2005 e 2009 (valores expressos em US\$ milhões)

\begin{tabular}{|c|c|c|c|c|c|c|}
\hline \multirow{2}{*}{ Países } & \multicolumn{2}{|c|}{2000} & \multicolumn{2}{|c|}{2005} & \multicolumn{2}{|c|}{2009} \\
\hline & Valor & $\%$ & Valor & $\%$ & Valor & $\%$ \\
\hline Resto do Mundo & 20.755 & $29,1 \%$ & 34.213 & $35,3 \%$ & 56.618 & $33,5 \%$ \\
\hline Estados Unidos & 11.541 & $16,2 \%$ & 12.406 & $12,8 \%$ & 20.434 & $12,1 \%$ \\
\hline Alemanha & 7.375 & $10,3 \%$ & 9.425 & $9,7 \%$ & 17.360 & $10,3 \%$ \\
\hline China & 1.335 & $1,9 \%$ & 5.415 & $5,6 \%$ & 16.774 & $9,9 \%$ \\
\hline França & 3.544 & $5,0 \%$ & 3.907 & $4,0 \%$ & 7.343 & $4,3 \%$ \\
\hline Itália & 3.659 & $5,1 \%$ & 3.734 & $3,9 \%$ & 6.676 & $4,0 \%$ \\
\hline Reino Unido & 1.714 & $2,4 \%$ & 2.860 & $3,0 \%$ & 5.988 & $3,5 \%$ \\
\hline Canadá & 4.013 & $5,6 \%$ & 2.635 & $2,7 \%$ & 5.269 & $3,1 \%$ \\
\hline Japão & 3.266 & $4,6 \%$ & 4.422 & $4,6 \%$ & 4.363 & $2,6 \%$ \\
\hline Coreia do Sul & 2.004 & $2,8 \%$ & 2.248 & $2,3 \%$ & 4.042 & $2,4 \%$ \\
\hline Bélgica & 1.198 & $1,7 \%$ & 1.247 & $1,3 \%$ & 2.401 & $1,4 \%$ \\
\hline Espanha & 1.440 & $2,0 \%$ & 1.872 & $1,9 \%$ & 2.324 & $1,4 \%$ \\
\hline México & 698 & $1,0 \%$ & 728 & $0,8 \%$ & 2.202 & $1,3 \%$ \\
\hline Holanda & 1.915 & $2,7 \%$ & 1.708 & $1,8 \%$ & 2.193 & $1,3 \%$ \\
\hline Taiwan & 933 & $1,3 \%$ & 1.249 & $1,3 \%$ & 2.153 & $1,3 \%$ \\
\hline India & 495 & $0,7 \%$ & 961 & $1,0 \%$ & 1.637 & $1,0 \%$ \\
\hline Finlândia & 602 & $0,8 \%$ & 980 & $1,0 \%$ & 1.526 & $0,9 \%$ \\
\hline Áustria & 360 & $0,5 \%$ & 525 & $0,5 \%$ & 1.385 & $0,8 \%$ \\
\hline Portugal & 759 & $1,1 \%$ & 922 & $1,0 \%$ & 1.377 & $0,8 \%$ \\
\hline Suécia & 932 & $1,3 \%$ & 1.057 & $1,1 \%$ & 1.283 & $0,8 \%$ \\
\hline Russia & 474 & $0,7 \%$ & 971 & $1,0 \%$ & 931 & $0,6 \%$ \\
\hline
\end{tabular}


conclusão.

\begin{tabular}{|c|c|c|c|c|c|c|}
\hline \multirow{2}{*}{ Países } & \multicolumn{2}{|c|}{2000} & \multicolumn{2}{|c|}{2005} & \multicolumn{2}{|c|}{2009} \\
\hline & Valor & $\%$ & Valor & $\%$ & Valor & $\%$ \\
\hline Indonésia & 328 & $0,5 \%$ & 330 & $0,3 \%$ & 793 & $0,5 \%$ \\
\hline Australia & 333 & $0,5 \%$ & 1.098 & $1,1 \%$ & 732 & $0,4 \%$ \\
\hline Dinamarca & 320 & $0,4 \%$ & 464 & $0,5 \%$ & 653 & $0,4 \%$ \\
\hline Irlanda & 291 & $0,4 \%$ & 221 & $0,2 \%$ & 438 & $0,3 \%$ \\
\hline Turquia & 76 & $0,1 \%$ & 129 & $0,1 \%$ & 425 & $0,3 \%$ \\
\hline Polônia & 103 & $0,1 \%$ & 172 & $0,2 \%$ & 402 & $0,2 \%$ \\
\hline República Tcheca & 111 & $0,2 \%$ & 277 & $0,3 \%$ & 350 & $0,2 \%$ \\
\hline Hungria & 148 & $0,2 \%$ & 165 & $0,2 \%$ & 295 & $0,2 \%$ \\
\hline Romênia & 42 & $0,1 \%$ & 95 & $0,1 \%$ & 135 & $0,1 \%$ \\
\hline Eslováquia & 17 & $0,0 \%$ & 43 & $0,0 \%$ & 122 & $0,1 \%$ \\
\hline Grécia & 72 & $0,1 \%$ & 125 & $0,1 \%$ & 112 & $0,1 \%$ \\
\hline Luxemburgo & 499 & $0,7 \%$ & 46 & $0,0 \%$ & 54 & $0,0 \%$ \\
\hline Eslovênia & 28 & $0,0 \%$ & 39 & $0,0 \%$ & 51 & $0,0 \%$ \\
\hline Bulgária & 9 & $0,0 \%$ & 67 & $0,1 \%$ & 45 & $0,0 \%$ \\
\hline Estônia & 8 & $0,0 \%$ & 14 & $0,0 \%$ & 45 & $0,0 \%$ \\
\hline Malta & 27 & $0,0 \%$ & 14 & $0,0 \%$ & 31 & $0,0 \%$ \\
\hline Letônia & 4 & $0,0 \%$ & 18 & $0,0 \%$ & 10 & $0,0 \%$ \\
\hline Lituânia & - & $0,0 \%$ & 4 & $0,0 \%$ & 4 & $0,0 \%$ \\
\hline Chipre & 3 & $0,0 \%$ & 2 & $0,0 \%$ & - & $0,0 \%$ \\
\hline Total & 71.431 & $100 \%$ & 96.808 & $100 \%$ & 168.976 & $100 \%$ \\
\hline
\end{tabular}

Fonte: Elaboração própria com base nos dados da WIOD.

Na análise comparativa entre três anos selecionados dos dados da Tabela 4, denotam-se mudanças significativas ocorridas nas relações comerciais brasileiras com dois dos seus principais parceiros, ${ }^{13}$ quais sejam: Estados Unidos e China, os quais merecem uma análise mais detalhada.

Observa-se queda significativa no peso relativo das importações brasileiras com origem nos Estados Unidos, principalmente na primeira metade da década, concomitantemente a um expressivo aumento na participação da China, que passou de $11^{\circ}$ maior parceiro comercial do Brasil em 2000 (considerando a amostra

13 De 2010 a 2013, dados de comércio exterior divulgados pela SECEX (Secretaria de Comércio Exterior do Ministério do Desenvolvimento, Indústria e Comércio Exterior) mostram que a concentração da pauta de importações nesses países cresceu ainda mais. Em 2009, a China aparecia como origem de cerca de 10\% do valor das importações, percentual que chegou a 29\% em 2013. Vale ressaltar que em 2012 a China superou os Estados Unidos e passou a ser o principal parceiro comercial brasileiro do ponto de vista das importações. 
dos 39 países da WIOD) ${ }^{14}$ para assumir o $3^{\circ}$ posto na pauta de importações brasileiras em 2009, atrás apenas dos Estados Unidos e Alemanha.

Tomando como referência as matrizes nacionais da WIOD destes dois países percebe-se que participação de insumos químicos no VBP agregado é bastante discrepante. Enquanto o valor dos insumos químicos representou, nos três anos em questão, 2,6\% em 2000, novamente 2,6\% em 2005 e 2,3\% em 2009 do valor de produção total norte-americana; no caso chinês, representou, respectivamente, 6,7\%, 7,3\% e 7,5\%. Sabemos que estas diferenças podem ser explicadas, em parte, tanto por decorrência do diferencial tecnológico e por diferenças na estrutura de preços relativos, ou ainda, um mix de ambos os fatores. Uma conclusão mais precisa sobre a responsabilidade de cada um destes fatores sobre tais diferenças requereria um estudo mais aprofundado sobre as duas economias, o que não é objetivo deste trabalho.

Vejamos quais setores tiveram maior peso na explicação deste crescimento da participação da China na pauta de importações brasileiras, verificando em que medida estas atividades são mais (ou menos) intensivas em insumos químicos. Ao longo da década de 2000, destaque para aumento da participação de produtos chineses nas importações brasileiras de "Textiles and textile products", "Leather, leather and footwear", "Chemicals and chemical products", "Rubber and Plastics", "Other non-metallic mineral", "Electrical and optical equipment" e "Machinery, nec". Juntas as importações deste conjunto de atividades totalizaram US\$978 milhões, US\$ 4,5 bilhões e US\$ 14,4 bilhões, em 2000, 2005 e 2009, respectivamente. Tais valores representaram para os respectivos anos, 73,2\%, 83,1\% e $86 \%$ do valor total importado da China.

A Tabela 5 apresenta a evolução nos três anos em análise dos valores exportados por cada uma destas atividades chinesas para o Brasil e seus respectivos pesos relativos na pauta de importações totais das referidas atividades.

14 Vale lembrar que um importante parceiro comercial brasileiro, a Argentina, não está entre os 39 países da base do WIOD, estando contemplado apenas no chamado "Resto do mundo". Segundo dados da Funcex, em 2000, a participação da Argentina nas importações totais brasileiras foi de $12,3 \%$, passando para 8,5\% em 2005 e 8,8\% em 2009. 
Tabela 5 - Importações brasileiras com origem na China - setores selecionados 2000, 2005 e 2009 (valores expressos em US\$ milhões)

\begin{tabular}{l|c|c|c|c|ccc}
\hline \multirow{2}{*}{\multicolumn{1}{c}{ Atividade }} & \multicolumn{2}{c}{$\mathbf{2 0 0 0}$} & \multicolumn{2}{c}{$\mathbf{2 0 0 5}$} & \multicolumn{2}{c}{$\mathbf{2 0 0 9}$} \\
\cline { 2 - 8 } & Valor & $\mathbf{\%}$ & Valor & \% & Valor & \% \\
\hline Textiles and textile products & 126 & 10,1 & 517 & 41,9 & 1.575 & 54,3 \\
Leather, leather and footwear & 28 & 11,8 & 86 & 30,4 & 320 & 49,1 \\
Chemicals and chemical products & 196 & 1,8 & 584 & 3,9 & 1.709 & 7,0 \\
Rubber and plastics & 35 & 2,6 & 130 & 6,5 & 452 & 13,8 \\
Other non-metallic mineral & 14 & 3,0 & 46 & 7,0 & 166 & 15,7 \\
Machinery, nec & 43 & 0,8 & 228 & 3,3 & 1.382 & 10,8 \\
Electrical and optical equipment & 535 & 4,2 & 2.932 & 19,0 & 8.833 & 36 \\
\hline
\end{tabular}

Fonte: Elaboração própria com base nos dados da WIOD.

Os dados evidenciam, por exemplo, que, se no início da década de todos os produtos têxteis estrangeiros que circulavam na economia brasileira apenas pouco mais de $10 \%$ eram chineses, no final da década, em 2009, esse percentual já era de 54,3\%. Esta inserção de produtos chineses na economia brasileira, no entanto, não se limitou a setores mais intensivos em trabalho, como é o caso do segmento têxtil. Chama atenção o fato de o forte aumento da presença de produtos chineses ter se dado de forma generalizada no mercado brasileiro. Ocorreu não apenas nos segmentos de menor conteúdo tecnológico, mas também naqueles mais intensos em capital e de maior conteúdo tecnológico, tais como os produtores de materiais elétricos e de máquinas e equipamentos.

Além disso, vale a ressalva de que entre todas as 35 atividades que compõem as matrizes do WIOD, apenas em três delas a participação chinesa no total importado sofreu quedas entre o início e o final do período em análise, quais sejam: "Mining and Quarrying" ( $0,3 \%$ das importações brasileiras de produtos da atividade extrativa mineral em 2000 frente a 0,2\% em 2009), "Coke, Refined Petroleum and nuclear fuel" (deixou de representar $2 \%$ do valor de importações brasileiras totais de combustíveis e coque em 2000 e passou a representar 1\% em 2009) e "Electricity, gas and water supply" (representava 0,9\% das aquisições estrangeiras desta atividade em 2000 e em 2009, 0,7\%). Todavia, os reduzidos percentuais indicam que nestas exceções os produtos chineses são pouco representativos na pauta de importações brasileiras e, por conseguinte, têm pouco impacto no cálculo das importações indiretas de químicos.

Comparando o percentual de insumos químicos da produção chinesa das atividades da Tabela 5 com o percentual médio (dos 39 países do WIOD) de insumos químicos no valor de produção destas mesmas atividades, denota-se que 
o primeiro apresenta valores significativamente superiores ao segundo, conforme apresentado na Tabela 6.

Tabela 6 - Razão entre insumos químicos e VBP da China e produção média global - setores selecionados - 2000, 2005 e 2009

\begin{tabular}{|c|c|c|c|c|c|c|}
\hline Atividades & \multicolumn{2}{|c|}{2000} & \multicolumn{2}{|c|}{2005} & \multicolumn{2}{|c|}{2009} \\
\hline Textiles and Textile Products & $6,8 \%$ & $8,2 \%$ & $7,3 \%$ & $9,1 \%$ & $6,9 \%$ & $7,8 \%$ \\
\hline Leather, Leather and Footwear & $6,9 \%$ & $6,3 \%$ & $6,4 \%$ & $8,1 \%$ & $5,9 \%$ & $7,4 \%$ \\
\hline Chemicals and Chemical Products & $24,4 \%$ & $30,8 \%$ & $24,2 \%$ & $32,9 \%$ & $23,5 \%$ & $33,6 \%$ \\
\hline Other Non-Metallic Mineral & $3,9 \%$ & $6,0 \%$ & $4,0 \%$ & $7,5 \%$ & $3,8 \%$ & $8,1 \%$ \\
\hline Machinery, Nec & $3,2 \%$ & $5,0 \%$ & $3,2 \%$ & $4,2 \%$ & $3,0 \%$ & $4,0 \%$ \\
\hline Electrical and Optical Equipment & $4,7 \%$ & $8,4 \%$ & $4,6 \%$ & $7,9 \%$ & $4,5 \%$ & $7,8 \%$ \\
\hline
\end{tabular}

Fonte: Elaboração própria com base nos dados da WIOD.

Dessa forma, com base nestes dados, pode-se inferir que a dinâmica de aumento da participação dos produtos chineses na pauta importações brasileiras ao longo da década de 2000 contribuiu para expandir o valor de importações indiretas de químicos da economia brasileira.

Já a queda no peso relativo de produtos provenientes dos Estados Unidos nas compras brasileiras do setor externo, que se deu de forma mais significativa entre 2000 e 2005, esteve principalmente calcada nas seguintes atividades: "Electrical and optical equipment", "Chemicals and chemical products" e "Machinery, nec". Estas atividades exportaram para o Brasil US \$ 7,4 bilhões em 2000, US \$ 6,4 bilhões em 2005 e US $\$ 9,3$ bilhões em 2009. Tais valores representaram em seus respectivos anos $64 \%, 51 \%$ e $46 \%$ do valor total importado pela economia brasileira dos Estados Unidos. A despeito da expressiva queda na participação agregada dos Estados Unidos nas importações brasileiras na primeira metade da década, chama atenção o crescimento significativo do peso relativo de produção norte-americana nas aquisições brasileiras de duas importantes atividades, a saber: "Transport equipment" e "Financial intermediation".

Já na segunda metade da década, encontramos maior grau de heterogeneidade no desempenho das atividades exportadoras norte-americanas para o Brasil. Por um lado, aquelas atividades que mais explicaram a retração dos Estados Unidos como local de origem das importações brasileiras na primeira metade da década apresentaram quedas mais amenas em seus pesos relativos; por outro, as duas atividades que na primeira década foram na contramão da tendência de queda da importância relativa das importações vindas dos Estados Unidos ("Transport equipment" e "Financial intermediation"15), também registraram reduções

15 A participação do peso relativo dos Estados Unidos como prestador dos serviços financeiros em 2009 certamente foi diretamente afetada pelos desdobramentos da crise financeira internacional eclodida nos próprios Estados Unidos em 2008. 
relativas significativas de sua presença nas importações brasileiras. Ademais, podemos identificar também importantes atividades que aumentaram sua participação relativa no mercado brasileiro, como é o caso do "Mining and quarrying", "Food, beverages and tobacco", "Coke, refined petroleum and nuclear fuel" e "Inland transport".

A Tabela 7 apresenta os valores exportados para o Brasil por cada uma das atividades norte-americanas referidas anteriormente, bem como a evolução do peso relativo destes valores no total importado pela economia brasileira nestas atividades.

Tabela 7 - Importações brasileiras com origem nos Estados Unidos - setores selecionados - 2000, 2005 e 2009 (valores expressos em US\$ milhões)

\begin{tabular}{|c|c|c|c|c|c|c|}
\hline \multirow{2}{*}{ Atividade } & \multicolumn{2}{|c|}{2000} & \multicolumn{2}{|c|}{2005} & \multicolumn{2}{|c|}{2009} \\
\hline & Valor & $\%$ & Valor & $\%$ & Valor & $\%$ \\
\hline Mining and quarrying & 151 & 2,6 & 525 & 4,8 & 1.211 & 8,2 \\
\hline Food, beverages and tobacco & 187 & 6,5 & 100 & 3,4 & 502 & 7,8 \\
\hline $\begin{array}{l}\text { Coke, refined petroleum and } \\
\text { nuclear fuel }\end{array}$ & 329 & 9,1 & 311 & 6,7 & 776 & 11,0 \\
\hline Chemicals and chemical products & 2.161 & 20,0 & 2.639 & 17,6 & 4.067 & 16,6 \\
\hline Machinery, nec & 1.188 & 22,8 & 1.330 & 19,4 & 2.334 & 18,3 \\
\hline Electrical and optical equipment & 4.073 & 32,0 & 2.382 & 15,4 & 2.928 & 11,9 \\
\hline Transport equipment & 1.194 & 19,3 & 1.657 & 21,6 & 2.746 & 16,6 \\
\hline Inland transport & 181 & 25,0 & 353 & 28,2 & 944 & 42,9 \\
\hline Financial intermediation & 127 & 17,9 & 968 & 66,2 & 1.531 & 53,0 \\
\hline
\end{tabular}

Fonte: Elaboração própria com base nos dados da WIOD.

O resultado que chama mais atenção diz respeito à atividade "Eletrical and optical equipment", a qual registrou a maior queda em termos relativos do valor importado pela economia brasileira, com retração de $20,1 \%$ na comparação 20002009 , além de queda no próprio valor nominal importado. Vale lembrar que esta atividade foi uma das que registraram um dos maiores avanços em termos da participação relativa de produção chinesa na pauta de importações brasileiras, 31,8\% entre 2000 e 2009. Com isso, é razoável supor que houve, em grande medida, um processo de substituição de origem de importação deste tipo de equipamento, produzido nos Estados Unidos por aqueles fabricados na China.

Vale apresentar o mesmo exercício comparativo dos percentuais de insumos químicos da produção norte-americana das atividades que tiveram as principais mudanças em termos de market-share de produtos estrangeiros no mercado 
brasileiro com o percentual médio global dos insumos químicos destas mesmas atividades.

Tabela 8 - Razão entre insumos químicos e VBP dos Estados Unidos e produção média global - setores selecionados - 2000, 2005 e 2009

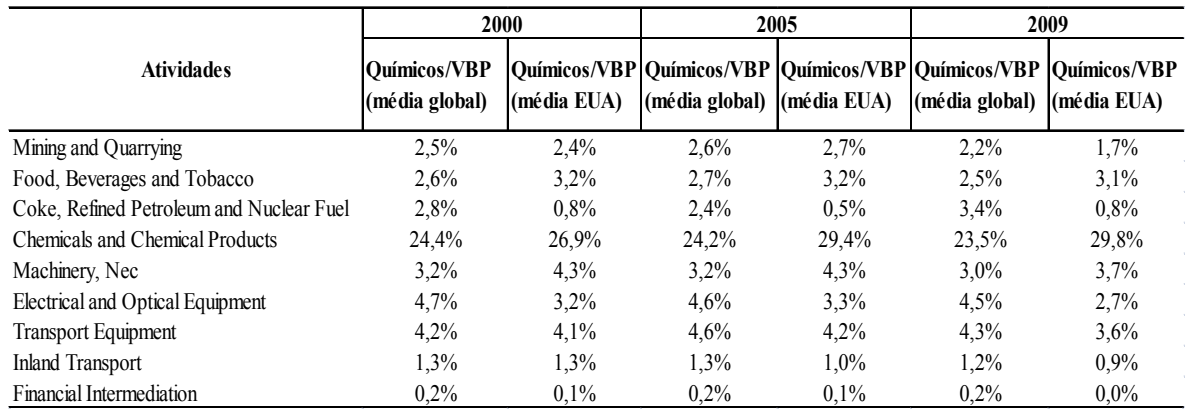

Fonte: Elaboração própria com base nos dados da WIOD.

Percebe-se que na atividade que explica parte expressiva da redução da presença de produtos norte-americanos na pauta de importações brasileiras na década de 2000, "Eletrical and optical equipment", o percentual do valor de químicos no VBP é inferior não apenas à média global, mas também ao percentual verificado na produção chinesa destes mesmos equipamentos (vide Tabela 6). Dessa forma, pode-se concluir que o referido movimento de substituição de origem das importações de produtos desta atividade contribuiu para elevar o valor das importações indiretas de químicos.

Dinâmicas semelhantes, porém, em magnitudes bem mais modestas, são encontradas em outras duas atividades, quais sejam: a própria "Chemical and chemical products" e "Machinery, nec". Diferentemente do que ocorreu com as importações de "Eletrical and optical equipment", no caso das atividades mencionadas, houve crescimento expressivo do valor nominal importado. No entanto, em função do crescimento ainda mais acelerado na penetração de produtos de outros países, entre os quais se destacam os provenientes da China, a participação dos produtos norte-americanos sofreu decréscimos. Em outras palavras, verificam-se movimentos opostos entre as participações relativas dos Estados Unidos e da China nas importações brasileiras. No caso dos "Chemical and chemical products" houve redução de 3,4\% na participação dos Estados Unidos e aumento de 5,2\% da participação chinesa. Quanto à "Machinery, nec", os números mostram retração de $4,6 \%$ do peso relativo de produtos norte-americanos e incremento de $10 \%$ na participação relativa de produtos provenientes da China no período em questão.

Nos dois últimos casos, em praticamente todo o período, com exceção para o dado de 2005 referente à atividade "Machinery, nec", os percentuais de insumos químicos na produção norte-americana foram menores que os percentuais na pro- 
dução chinesa. Contudo, vale ressaltar que quando comparados com a produção média global, os coeficientes norte-americanos de participação de químicos apresentam valores inferiores em relação à fabricação nos Estados Unidos.

Em síntese, verifica-se realmente que houve expressiva perda de espaço na pauta de importações brasileiras de produtos industriais norte-americanos que, de forma geral, apresentavam processos mais eficientes do ponto de vista da utilização de insumos químicos. Onde a produção norte-americana realmente incrementou significativamente o peso nas importações brasileiras ocorreu em atividades de serviços, em particular no "Inland transport" e "Financial intermediation", as quais requerem valores de insumos químicos muito pouco expressivos em seus respectivos processos produtivos.

Passemos finalmente à apresentação dos valores finais de importações indiretas de químicos estimados a partir dos dados internacionais de insumo-produto do WIOD. Do ponto de vista agregado, em 2000, as importações indiretas de químicos somaram US $\$ 5$ bilhões, passando para US $\$ 6,7$ bilhões em 2005 e US $\$ 11,2$ bilhões em 2009. A Tabela 9 traz os valores dos dados desagregados das importações indiretas de químicos por país, bem como o peso relativo destes países na absorção destas importações. 
Tabela 9 - Estimação das importações brasileiras indiretas de químicos por origem - 2000, 2005 e 2009 (valores expressos em US\$ milhões)

\begin{tabular}{|c|c|c|c|c|c|c|}
\hline \multirow{2}{*}{ Países } & \multicolumn{2}{|c|}{2000} & \multicolumn{2}{|c|}{2005} & \multicolumn{2}{|c|}{2009} \\
\hline & Valor & $\%$ & Valor & $\%$ & Valor & $\%$ \\
\hline Resto do Mundo & 1.652 & $33,1 \%$ & 2.252 & $33,8 \%$ & 3.320 & $29,7 \%$ \\
\hline Estados Unidos & 945 & $18,9 \%$ & 1.144 & $17,2 \%$ & 1.754 & $15,7 \%$ \\
\hline Alemanha & 368 & $7,4 \%$ & 458 & $6,9 \%$ & 755 & $6,8 \%$ \\
\hline China & 147 & $2,9 \%$ & 588 & $8,8 \%$ & 1.820 & $16,3 \%$ \\
\hline França & 241 & $4,8 \%$ & 284 & $4,3 \%$ & 392 & $3,5 \%$ \\
\hline Itália & 219 & $4,4 \%$ & 233 & $3,5 \%$ & 313 & $2,8 \%$ \\
\hline Reino Unido & 112 & $2,2 \%$ & 140 & $2,1 \%$ & 199 & $1,8 \%$ \\
\hline Canadá & 99 & $2,0 \%$ & 101 & $1,5 \%$ & 127 & $1,1 \%$ \\
\hline Japão & 191 & $3,8 \%$ & 223 & $3,3 \%$ & 361 & $3,2 \%$ \\
\hline Coreia do Sul & 197 & $3,9 \%$ & 210 & $3,1 \%$ & 401 & $3,6 \%$ \\
\hline Bélgica & 92 & $1,8 \%$ & 95 & $1,4 \%$ & 138 & $1,2 \%$ \\
\hline Espanha & 118 & $2,4 \%$ & 145 & $2,2 \%$ & 220 & $2,0 \%$ \\
\hline México & 63 & $1,3 \%$ & 72 & $1,1 \%$ & 193 & $1,7 \%$ \\
\hline Holanda & 94 & $1,9 \%$ & 82 & $1,2 \%$ & 109 & $1,0 \%$ \\
\hline Taiwan & 108 & $2,2 \%$ & 154 & $2,3 \%$ & 284 & $2,5 \%$ \\
\hline India & 74 & $1,5 \%$ & 128 & $1,9 \%$ & 184 & $1,6 \%$ \\
\hline Finlândia & 22 & $0,4 \%$ & 25 & $0,4 \%$ & 44 & $0,4 \%$ \\
\hline Áustria & 23 & $0,5 \%$ & 25 & $0,4 \%$ & 62 & $0,6 \%$ \\
\hline Portugal & 14 & $0,3 \%$ & 15 & $0,2 \%$ & 26 & $0,2 \%$ \\
\hline Suécia & 36 & $0,7 \%$ & 40 & $0,6 \%$ & 54 & $0,5 \%$ \\
\hline Russia & 62 & $1,2 \%$ & 85 & $1,3 \%$ & 144 & $1,3 \%$ \\
\hline
\end{tabular}




\begin{tabular}{|c|c|c|c|c|c|c|}
\hline \multirow{2}{*}{ Países } & \multicolumn{2}{|c|}{2000} & \multicolumn{2}{|c|}{2005} & \multicolumn{2}{|c|}{2009} \\
\hline & Valor & $\%$ & Valor & $\%$ & Valor & $\%$ \\
\hline Indonésia & 31 & $0,6 \%$ & 31 & $0,5 \%$ & 71 & $0,6 \%$ \\
\hline Australia & 11 & $0,2 \%$ & 14 & $0,2 \%$ & 14 & $0,1 \%$ \\
\hline Dinamarca & 17 & $0,3 \%$ & 18 & $0,3 \%$ & 28 & $0,2 \%$ \\
\hline Irlanda & 11 & $0,2 \%$ & 14 & $0,2 \%$ & 39 & $0,4 \%$ \\
\hline Turquia & 7 & $0,1 \%$ & 12 & $0,2 \%$ & 22 & $0,2 \%$ \\
\hline Polônia & 11 & $0,2 \%$ & 18 & $0,3 \%$ & 26 & $0,2 \%$ \\
\hline República Tcheca & 5 & $0,1 \%$ & 26 & $0,4 \%$ & 29 & $0,3 \%$ \\
\hline Hungria & 7 & $0,1 \%$ & 8 & $0,1 \%$ & 16 & $0,1 \%$ \\
\hline Romênia & 1 & $0,0 \%$ & 3 & $0,0 \%$ & 9 & $0,1 \%$ \\
\hline Eslováquia & 1 & $0,0 \%$ & 3 & $0,0 \%$ & 7 & $0,1 \%$ \\
\hline Grécia & 1 & $0,0 \%$ & 3 & $0,0 \%$ & 2 & $0,0 \%$ \\
\hline Luxemburgo & 1 & $0,0 \%$ & 3 & $0,0 \%$ & 2 & $0,0 \%$ \\
\hline Eslovênia & 4 & $0,1 \%$ & 2 & $0,0 \%$ & 4 & $0,0 \%$ \\
\hline Bulgária & 1 & $0,0 \%$ & 12 & $0,2 \%$ & 5 & $0,0 \%$ \\
\hline Estônia & 2 & $0,0 \%$ & 1 & $0,0 \%$ & 2 & $0,0 \%$ \\
\hline Malta & 0 & $0,0 \%$ & 0 & $0,0 \%$ & 1 & $0,0 \%$ \\
\hline Letônia & 0 & $0,0 \%$ & 0 & $0,0 \%$ & 1 & $0,0 \%$ \\
\hline Lituânia & 0 & $0,0 \%$ & 0 & $0,0 \%$ & 0 & $0,0 \%$ \\
\hline Chipre & 0 & $0,0 \%$ & 0 & $0,0 \%$ & 0 & $0,0 \%$ \\
\hline Total & 4.991 & $98 \%$ & 6.668 & $97 \%$ & 11.180 & $98 \%$ \\
\hline
\end{tabular}

Fonte: Elaboração própria com base nos dados da WIOD.

Como esperado, as importações indiretas de químicos provenientes da China mostraram forte expansão ao longo do período. A despeito de a China ser o terceiro país do qual a economia brasileira mais importava em 2009, as importações indiretas de químicos chinesas já superavam as com origem nos Estados Unidos e Alemanha no fim da década passada. 
Vale, no entanto, ressaltar que a queda nas participações norte-americanas na pauta de importação brasileira foi mais acentuada que a redução deste mesmo país nas importações indiretas de químicos. Um dos principais elementos que justificam esta menor queda na participação dos Estados Unidos nas importações indiretas brasileiras de químicos diz respeito à manutenção de elevada participação dos "Chemicals and chemical products" nas exportações totais dos Estados Unidos para o Brasil. ${ }^{16}$ E como já mostrado anteriormente, o coeficiente de insumos químicos na produção desta atividade nos Estados Unidos é relativamente elevado (ver Tabela 8), sendo superior ao coeficiente médio dos países do WIOD.

Convertendo estes valores em US\$ para R \$ por meio da taxa média de câmbio anual, ${ }^{17}$ obtivemos novos valores para as importações indiretas. A Tabela 10 traz estes valores, bem como a comparação com aqueles obtidos na primeira estimação a partir das matrizes brasileiras.

Tabela 10 - Estimação das importações brasileiras indiretas de químicos - 2000, 2005 e 2009 - (valores expressos em R \$ milhões)

\begin{tabular}{lccc}
\hline \multicolumn{1}{c}{ Estimação por fonte } & $\mathbf{2 0 0 0}$ & $\mathbf{2 0 0 5}$ & \multicolumn{1}{c}{$\mathbf{2 0 0 9}$} \\
\hline MIPs brasileiras & 12.511 & 22.602 & 28.215 \\
MIPs internacionais & 9.131 & 16.230 & 22.267 \\
\hline Diferença & $\mathbf{3 . 3 8 0}$ & $\mathbf{6 . 3 7 2}$ & $\mathbf{5 . 9 4 8}$ \\
\hline
\end{tabular}

Fonte: Elaboração própria com base nos dados do IBGE e WIOD.

É bem verdade que parte da diferença deve-se ao fato de que as importações totais brasileiras na base do WIOD estão abaixo daquelas apresentadas pelas MIPs brasileiras, como já comentado. No entanto, em termos percentuais, as diferenças nas estimativas das importações indiretas de químicos são muito mais expressivas que as diferenças encontradas nas importações totais. Portanto, pode-se dizer que a maior parte do diferencial está associada a outros elementos, tais como distintas estruturas produtivas/tecnológicas e diferenças nos preços relativos.

Em 2000, a diferença foi menos expressiva do que aquelas encontradas na metade e no fim da década, indicando que a estrutura produtiva, tecnológica, assim como de preços relativos, em particular no que tange à indústria química no Brasil, era mais próxima daquela encontrada no restante do mundo no início da década. No entanto, em termos da variação, ambas estimativas apontam para um forte crescimento no período em análise, sendo a primeira resultante em uma expansão média de 9,5\% ao ano e a segunda, de 10,4\% ao ano.

16 Em 2000, estes produtos representavam 18,7\% do valor total exportado dos Estados Unidos para o Brasil. Em 2005, este percentual passou a ser de 21,3\%, sofrendo uma queda para 19,9\% em 2009.

17 Lembrando que a referência utilizada foi a média da taxa de câmbio PTAX de venda. Admitindo a conversão de R\$ para US\$, a taxa em 2000 foi de 1,83, em 2005, 2,43 e em 2009, 1,99. 
Fazendo o corte temporal em 2005 e calculando a taxa média de crescimento nominal anual (em US\$) das importações indiretas de químicos na primeira e segunda metade da década, também se verifica uma taxa mais expressiva na primeira metade do que na segunda. Entre 2000 e 2005, a expansão foi de 12,2\% ao ano (próxima à taxa de 12,6\% a.a. obtida com a estimativa por meio das MIP brasileiras) e 8,2\% a.a., significativamente acima do crescimento de 5,7\% a.a. na estimativa apresentada na seção anterior.

Um dos principais elementos que explica este descompasso entre as duas taxas calculadas para a segunda metade da década está na aceleração da penetração de importações chinesas de produtos de atividades relativamente mais intensivas em insumos químicos, quais sejam: os próprios "Chemicals and chemicals products" e "Rubber and plastics". Como já mostrado, a participação de produtos chineses nas importações brasileiras nestes dois últimos casos acelerou- se bastante na segunda metade da década (ver Tabela 5). Tais produtos quando produzidos na China apresentaram um percentual de insumos químicos muito superior à média global (ver Tabela 6) e àquele apresentado pela produção nacional. ${ }^{18}$

Neste sentido, é plausível supor que a própria substituição de produção local por importação de insumos químicos, na qual os produtos chineses tiveram grande destaque, contribui também para elevar as importações indiretas destes mesmos insumos.

Em suma, os valores estimados de importações indiretas foram bastante expressivos quando comparados às importações diretas destes produtos. Tomando como referência as estimativas com as MIP brasileiras, as importações indiretas representaram nos anos de 2000, 2005 e 2009, 57,8\%, 54,4\% e 48,7\%, respectivamente. Considerando o cálculo a partir das MIP do WIOD, os percentuais foram um pouco menores, mas ainda significativos, sendo de $42,2 \%, 39,1 \%$ e $38,5 \%$, respectivamente.

\section{Considerações Finais}

O objetivo deste artigo foi estimar as importações brasileiras indiretas de químicos para diferentes anos da década de 2000. Para isso, utilizou-se uma base nacional e outra internacional de MIP.

A estimativa feita com base nas MIPs brasileiras apontou para importações indiretas crescentes, saindo de $R \$ 12,5$ bilhões em 2000 , passando a $R \$ 22,6$ bilhões e alcançando $R \$ 28,2$ bilhões em 2009 . Vale ressaltar que na primeira meta-

18 No caso dos "Chemicals and chemical products", o peso relativo de insumos químicos no valor de produção brasileira em 2005, por exemplo, era de 25,4\%, caindo para 21,5\% em 2009. Com relação à atividade "Rubber and plastics", a participação de insumos químicos em 2005 era de $35 \%$, enquanto em 2009 , de $28,3 \%$. 
de da década (2000-2005) a desvalorização cambial contribuiu para a expansão do valor, uma vez que elevou os preços dos importados na moeda nacional, ao passo que na segunda metade (2005-2009), com a valorização cambial, a expansão no valor em $R \$$ foi, em grande medida, explicada pela expansão no volume das importações.

Os resultados apontaram para o aumento na parcela de insumos químicos importados no valor da produção da economia brasileira, em particular nas atividades mais intensivas em produtos químicos, tais como "Resinas e elastômeros", "Defensivos agrícolas" e "Produtos e preparados químicos diversos".

Já a segunda estimativa, a qual levou em consideração as estruturas econômicas dos países de origem das importações brasileiras, resultou em valores inferiores de importações indiretas. Em 2000, tais importações foram de R 9,1 bilhões, passando a $R \$ 16,2$ bilhões em 2005 e alcançando $R \$ 22,3$ bilhões em 2009.

$\mathrm{Na}$ análise destes últimos resultados, denotou-se também queda significativa no peso relativo das importações brasileiras com origem nos Estados Unidos, principalmente na primeira metade da década, concomitantemente a um expressivo aumento da participação chinesa.

A dinâmica de aumento da participação de produtos chineses na pauta de importações brasileiras contribuiu para a expansão do valor de importações indiretas de químicos do Brasil, uma vez que a participação de químicos na produção chinesa naquelas atividades que se destacaram na pauta de importações brasileiras mostrou-se acima da média global. Os dados sinalizaram que, ao longo dos anos 2000, a produção chinesa tomou espaço não apenas da produção nacional no mercado brasileiro, mas também da produção norte-americana.

A ampla diferença nos valores entre as duas estimativas ajuda a revelar a defasagem da estrutura produtiva e tecnológica da economia brasileira em relação ao resto do mundo. A despeito da aceleração na penetração de produtos chineses que apresentaram maior utilização de insumos químicos por unidade monetária produzida, a diferença entre as duas estimativas se manteve elevada ao longo de toda a década.

Parte da diferença deve-se a questões associadas a diferenças nos preços relativos. Entretanto, dada a defasagem em termos de produtividade e competitividade da economia brasileira em comparações internacionais, ${ }^{19}$ é plausível concluir que parte expressiva do diferencial dos dois métodos deve-se a diferenças na estrutura produtiva/tecnológica brasileira em relação aos seus parceiros comerciais. Dado o baixo crescimento da produtividade e os problemas de competitividade, é razoável afirmar que a estrutura produtiva/tecnológica da economia brasileira

19 Para mais detalhes sobre o comparativo internacional de produtividade do trabalho da economia brasileira, ver Miguez e Moreira (2014). Para mais informações sobre os problemas associados à competitividade na economia brasileira, em particular do setor industrial, ver Campelo Júnior e Sales (2011). 
se encontra em níveis defasados em termos internacionais. Com isso, utilizando a estrutura produtiva brasileira para o cálculo de importações indiretas efetivas, é possível dizer que o valor obtido esteja superestimado.

Somando a estimativa de importações indiretas às diretas de produtos químicos podemos ter uma ideia da dimensão do mercado potencial total de produtos químicos que acaba sendo deslocado pelas importações totais do país. Utilizando a estimativa das importações indiretas feitas a partir das MIP internacionais, no referido mercado para os anos de 2000, 2005 e 2009, foram de $R \$ 30,7$ bilhões, $R \$ 57,5$ bilhões e $\mathrm{R} \$ 80,1$ bilhões, respectivamente. Este mesmo mercado mensurado com base nas importações indiretas estimadas a partir das MIP nacionais foi de $\mathrm{R} \$ 34,1$ bilhões, $R \$ 63,9$ bilhões e $\mathrm{R} \$ 86$ bilhões para os referidos anos, respectivamente.

Embora os números calculados com base nas MIP internacionais possam ser mais precisos em termos do valor efetivamente importado de produtos químicos, quando se pretende utilizar a estimativa de importações indiretas visando mensurar um mercado potencial para os produtos químicos na hipótese de a demanda por importações fosse suprida por produção nacional, a estimativa a partir das MIP brasileiras pode ser a mais indicada. Neste caso, uma interessante extensão do presente trabalho seria o dimensionamento do volume de investimentos a serem feitos pela indústria química nas situações em que a produção local de certas atividades econômicas possa ser ampliada ou, eventualmente, substituir importações. Para tanto, torna-se necessária a estimação de alguma relação capital/produto para as atividades da indústria química, o que também encontra outros obstáculos, uma vez que não existem estimativas oficiais para os estoques de capital setoriais no país.

Por fim, o trabalho buscou, ao menos, evidenciar que, a partir do amplo grau de dispersão dos insumos químicos nas diversas cadeias produtivas da economia brasileira, é possível criar mercados de tamanho relevante para produtos da indústria química induzidos pela redução no coeficiente de importação, não apenas restrito à indústria química, mas em diversas outras atividades econômicas.

\section{Referências}

ABDON, A.; BACATE, M.; FELIPE, J.; KUMAR, U. Product complexity and economic development. New York: Levy Economics Institute, 2010. (Working Paper n. 116).

ASSOCIAÇÃO BRASILEIRA DA INDÚSTRIA QUÍMICA - ABIQUIM. Perspectiva de Investimento 2010-2013. São Paulo, 2010a.

. Pacto nacional da indústria química. São Paulo, 2010b.

BRESSER-PEREIRA, L. C. Macroeconomia da estagnação: crítica da ortodoxia convencional no Brasil pós-1994. São Paulo: Editora 34, 2007. 
BRESSER-PEREIRA, L. C.; GALA, P. Macroeconomia estruturalista do desenvolvimento. Revista de Economia Política, v.30, n. 4, p. 663-686, 2010.

CAMPELO JÚNIOR.; A; SALES, S. Produtividade e competitividade da indústria brasileira de 1996 a 2010. In: BONELLI, R. (Org.). A agenda de competitividade do Brasil. Rio de Janeiro: FGV, 2011.

CARVALHO, F. C. Entendendo a recente crise financeira global. In: ASSOCIAÇÃO KEYNESIANA BRASILEIRA. Dossiê da crise. Porto Alegre: AKB, 2008.

DIETZENBACHER, E., LOS, B., STEHRER, R., TIMMER, M., VRIES, G. The Construction of world input-output tables in the WIOD project. Economic Systems Research, v. 25 , n. 1, p. 71-98, 2013.

FEIJÓ, C. A.; RAMOS, R. L. O. Contabilidade Social: a nova referência das contas nacional do Brasil. 3. ed. Rio de Janeiro: Editora Campus-Elsevier, 2008.

FERRARI FILHO, F. F.; PAULA, L. F. de. Pode "Ela" acontecer de novo? In: ASSOCIAÇÃO KEYNESIANA BRASILEIRA. Dossiê da Crise. Porto Alegre: AKB, 2008.

GUILHOTO, J. J. M. et al. Matriz de insumo-produto do Nordeste e estados: metodologia e resultados. Fortaleza: Banco do Nordeste do Brasil, 2010.

GUILHOTO, J. J. M.; SONIS, M.; HEWINGS, G. J. D.; MARTINS, E. B. Índices de ligações e setores chave na economia brasileira: 1959-1980. Pesquisa e Planejamento Econômico, v. 2, n. 24 , p. 287-314, 1994.

HAUSMANN, R. et al. The atlas of economics complexity - Mapping paths to prosperity. New York: Puritan Press, 2011.

HIDALGO, C.; HAUSMANN, R. The building blocks of economic complexity. Proceedings of the National Academy of Sciences, v. 26, n. 106, p. 10570-10575, 2009.

HIRSCHMAN, A. O. The strategy of economic development. New Haven: Yale University Press, 1958.

IBGE. Pesquisa Industrial Anual (PIA). Dados por unidade da federação. Brasília, DF: IBGE, 2009.

MARTINEZ, T. S. Método RAWS/RAW para estimação anual da Matriz de Insumo-Produto na referência 2000 das Contas Nacionais. Brasília: Ipea, 2015. (Texto para Discussão n. 2043).

MIGUEZ, T.; MOREIRA, T. M. Produtividade do trabalho e mudança estrutural: Uma comparação internacional com base no World Input-Output Database (WIOD) 19952009. In: NEGRI, F.; CAVALCANTE, L. R. (Org.). Produtividade no Brasil: desempenho e determinantes. v. 1 - Desempenho. Brasília, DF: ABDI: Ipea, 2014.

MILLER, R. E.; BLAIR, P. D. Input-output analysis: foundations and extensions. 2. ed. New York: Cambridge University Press, 2009. 
MOREIRA, T. M.; RIBEIRO, L. C. S. Mudanças estruturais na economia brasileira entre 20002005 e o novo regime macroeconômico: uma abordagem multissetorial. Revista Economia, v. 14, n. 1C, p. 751-780, 2013.

MOREIRA, T. M.; VERGES, P. H.; RIBEIRO, L. C. S. Encadeamentos produtivos do complexo sucroalcooleiro no Brasil: a década de 2000 em uma nova abordagem da matriz insumoproduto. Pesquisa e Planejamento Econômico, v. 44, n. 2, p. 405-460, 2014.

PRADO, E. F. S. Estrutura tecnológica e desenvolvimento regional. São Paulo: IPE/USP, 1981.

RASMUSSEN, P. N. Studies in intersectoral relations. Amsterdan: North Holland, 1958.

RIBEIRO, L. C. S. O impacto econômico dos materiais recicláveis das cooperativas de catadores no estado do Rio de Janeiro em 2006: uma análise de insumo-produto. 2010. Dissertação (Mestrado em Economia) - Faculdade de Ciências Econômicas, Universidade Federal da Bahia, Salvador, 2010.

RIBEIRO, L. C. S. et al. Economia baiana em 2005 sob a ótica das relações intersetoriais: uma abordagem insumo-produto. Revista Desenbahia, n. 12, p. 41-66, 2010.

TIMMER, M. P. et al. An illustrated user guide to the World Input-Output Database: the case of global automotive production. Review of International Economics, v. 23, n. 3, p. 575-605, 2015. 


\section{Anexo A - Correspondência das atividades da matriz da WIOD com a matriz brasileira}

\begin{tabular}{|c|c|}
\hline Setores de Atividade do IBGE - SCN & Setores de Atividade WIOD \\
\hline $\begin{array}{l}1 \text { Agricultura, silvicultura, exploração florestal } \\
2 \text { Pecuária e pesca }\end{array}$ & (1+2) Agriculture, Hunting, Forestry and Fishing \\
\hline $\begin{array}{ll}3 & \text { Petróleo e gás natural } \\
4 & \text { Minério de ferro } \\
5 & \text { Outros da indústria extrativa }\end{array}$ & $(3+4+5)$ Mining and Quarrying \\
\hline $\begin{array}{l}6 \text { Alimentos e bebidas } \\
7 \text { Produtos do fumo }\end{array}$ & (6+7) Food, Beverages and Tobacco \\
\hline $\begin{array}{l}8 \text { Têxteis } \\
9 \text { Artigos do vestuário e acessórios }\end{array}$ & $(8+9)$ Textiles and Textile Products \\
\hline 10 Artefatos de couro e calçados & (10) Leather, Leather and Footwear \\
\hline 11 Produtos de madeira - exclusive móveis & (11) Wood and Products of Wood and Cork \\
\hline $\begin{array}{l}12 \text { Celulose e produtos de papel } \\
13 \text { Jornais, revistas, discos }\end{array}$ & $(12+13)$ Pulp, Paper, Paper, Printing and Publishing \\
\hline $\begin{array}{l}14 \text { Refino de petróleo e coque } \\
15 \text { Álcool }\end{array}$ & $(14+15)$ Coke, Refined Petroleum and Nuclear Fuel \\
\hline $\begin{array}{l}16 \text { Produtos químicos } \\
17 \text { Fabricação de resina e elastômeros } \\
18 \text { Produtos farmacêuticos } \\
19 \text { Defensivos agrícolas } \\
20 \text { Perfumaria, higiene e limpeza } \\
21 \text { Tintas, vernizes, esmaltes e lacas } \\
22 \text { Produtos e preparados químicos diversos }\end{array}$ & $(16+17+18+19+20+21+22)$ Chemicals and Chemical Products \\
\hline 23 Artigos de borracha e plástico & (23) Rubber and Plastics \\
\hline $\begin{array}{l}24 \text { Cimento } \\
25 \text { Outros produtos de minerais não-metálicos }\end{array}$ & $(24+25)$ Other Non-Metallic Mineral \\
\hline $\begin{array}{l}26 \text { Fabricação de aço e derivados } \\
27 \text { Metalurgia de metais não-ferrosos } \\
28 \text { Produtos de metal - exclusive máquinas e equipamentos }\end{array}$ & $(26+27+28)$ Basic Metals and Fabricated Metal \\
\hline $\begin{array}{l}29 \text { Máquinas e equipamentos, inclusive manutenção e reparos } \\
30 \text { Eletrodomésticos } \\
31 \text { Máquinas para escritório e equipamentos de informática } \\
32 \text { Máquinas, aparelhos e materiais elétricos }\end{array}$ & $(29+30+31+32)$ Machinery, $\mathrm{Nec}$ \\
\hline $\begin{array}{l}33 \text { Material eletrônico e equipamentos de comunicações } \\
34 \text { Aparelhos/instrumentos médico-hospitalar, medida e óptico }\end{array}$ & (33+34) Electrical and Optical Equipment \\
\hline $\begin{array}{l}35 \text { Automóveis, camionetas e utilitários } \\
36 \text { Caminhões e ônibus } \\
37 \text { Peças e acessórios para veículos automotores } \\
38 \text { Outros equipamentos de transporte }\end{array}$ & $(35+36+37+38)$ Transport Equipment \\
\hline $\begin{array}{l}39 \text { Móveis e produtos das indústrias diversas } \\
40 \text { Eletricidade e gás, água, esgoto e limpeza urbana } \\
41 \text { Construção }\end{array}$ & $\begin{array}{l}\text { (39) Manufacturing, Nec; Recycling } \\
\text { (40) Electricity, Gas and Water Supply } \\
\text { (41) Construction }\end{array}$ \\
\hline 42 Comércio & $\begin{array}{l}\text { (42) Sale, Maintenance and Repair of Motor Vehicles and Motorcycles; Retail Sale of Fuel } \\
\text { (42) Wholesale Trade and Commission Trade, Except of Motor Vehicles and Motorcycles }\end{array}$ \\
\hline $\begin{array}{l}47 \text { Serviços de manutenção e reparação } \\
48 \text { Serviços de alojamento e alimentação }\end{array}$ & $\begin{array}{l}\text { (47) Retail Trade, Except of Motor Vehicles and Motorcycles; Repair of Household Goods } \\
\text { (48) Hotels and Restaurants }\end{array}$ \\
\hline 43 Transporte, armazenagem e correio & $\begin{array}{l}\text { (43) Inland Transport } \\
\text { (43) Water Transport } \\
\text { (43) Air Transport } \\
\text { (43) Other Supporting and Auxiliary Transport Activities; Activities of Travel Agencies }\end{array}$ \\
\hline 44 Serviços de informação & (44) Post and Telecommunications \\
\hline 45 Intermediação financeira e seguros & (45) Financial Intermediation \\
\hline 46 Serviços imobiliários e aluguel & (46) Real Estate Activities \\
\hline 49 Serviços prestados às empresas & (49) Renting of M\&Eq and Other Business Activities \\
\hline 50 Educação mercantil & (50) Education \\
\hline 51 Saúde mercantil & (51) Health and Social Work \\
\hline $\begin{array}{l}52 \text { Outros serviços } \\
53 \text { Educação pública } \\
54 \text { Saúde pública }\end{array}$ & $(52+53+54)$ Other Community, Social and Personal Services \\
\hline 55 Administração pública e seguridade social & (55) Public Admin and Defence; Compulsory Social Security \\
\hline
\end{tabular}

Fonte: Elaboração própria com base no ISIC (rev.3) e CNAE 1.0.

Recebido em: 29/02/2016.

Aceito em: 29/08/2016. 